Article

\title{
Synthesis and Antibacterial Activities of Novel 4-Hydroxy-7-hydroxy- and 3-Carboxycoumarin Derivatives
}

Pen-Yuan Lin ${ }^{1}$, Kuang-Sheng Yeh ${ }^{2}$, Chien-Ling Su ${ }^{3}$, Shiow-Yunn Sheu ${ }^{1}$, Tiffany Chen ${ }^{4}$, Keng-Liang Ou ${ }^{5}$, Mei-Hsiang Lin ${ }^{1}$ and Lin-Wen Lee ${ }^{6, *}$

1 School of Pharmacy, College of Pharmacy, Taipei Medical University, 250 Wuxing St., Taipei 11031, Taiwan

2 Department of Veterinary Medicine, School of Veterinary Medicine, College of Bioresources and Agriculture, National Taiwan University, No. 1, Sec. 4, Roosevelt Rd., Taipei 10617, Taiwan

3 School of Respiratory Therapy, Taipei Medical University, Taipei Medical University, 250 Wuxing St., Taipei 11031, Taiwan

4 Department of Biochemistry and Chemistry, University of Washington, 4311 11th Ave. NE, Seattle, WA 98105-4068, USA

5 Research Center for Biomedical Devices and Prototyping Production, Taipei Medical University, 250 Wuxing St., Taipei 11031, Taiwan

6 Department of Microbiology and Immunology, School of Medicine, College of Medicine, Taipei Medical University, 250 Wuxing St., Taipei 11031, Taiwan

* Author to whom correspondence should be addressed; E-Mail: lucie@tmu.edu.tw;

Tel.: +886-227-361-661 (ext. 3917); Fax: +886-229-278-316.

Received: 29 June 2012; in revised form: 20 August 2012 / Accepted: 3 September 2012 /

Published: 10 September 2012

Abstract: Coumarin derivatives are used as fluorescent dyes and medicines. They also have some notable physiological effects, including the acute hepatoxicity and carcinogenicity of certain aflatoxins, the anticoagulant action of dicoumarol, and the antibiotic activity of novobicin and coumerymycin A1. Because the number of drug resistant strains is increasing at present, the synthesis of new antibacterial compounds is one of the critical methods for treating infectious diseases. Therefore, a series of coumarinsubstituted derivatives, namely 4-hydroxy- and 7-hydroxycoumarins, and 3-carboxycoumarins were synthesized. 4-Hydroxycoumarin derivatives $4 \mathbf{a}-\mathbf{c}$ underwent rearrangement reactions. Both 4- and 7-hydroxycoumarins were treated with activated aziridines which produced series of ring-opened products 7, 8, 10, and 11. 3-Carboxy-coumarin amide dimer derivatives 14-21 were prepared by reacting aliphatic alkylamines and 
alkyldiamines with PyBOP and DIEA. In this study, we use a new technique called modified micro-plate antibiotic susceptibility test method (MMAST), which is more convenient, more efficient, and more accurate than previous methods and only a small amount of the sample is required for the test. Some of the compounds were produced by reactions with acid anhydrides and demonstrated the ability to inhibit Gram-positive microorganisms. The dimer derivatives displayed lower antibacterial activities.

Keywords: 4-hydroxy-; 7-hydroxy-; 3-carboxycoumarin derivatives; antibacterial activities

\section{Introduction}

Coumarin is a lactone compound which is widely distributed in plants and can be extracted, among others, from Anthoxanthum odoratum, Melilotus officinalis, Dipterix oppositifolia and Dipterix oppositifolia [1]. Its derivatives are used as daylight fluorescent pigments [2], brighteners [3], fluorescent dyes [4], fluorescent sensors [5], laser dyes [6], drug carriers [7], and drug delivery agents [8]. Recently, various medicinal effects, such as anticoagulant $[9,10]$, analytical fluorescence indicator, anti-inflammatory [11] and antioxidant [12-15] properties have been reported. Many authors have reported the convenient and effective synthesis of the dimers from salicylaldehydes and by biomimetic synthesis. Acetoxycoumarins, polycyclic 7-hydroxycoumarins and other coumarin derivatives display anticarcinogenic properties [16-22]. Roma also reported that tricyclic or bicyclic coumarin derivatives with amino groups showed antiplatelet activity [23]. 4-Heteroarylamino-, triazolopyridine, imidazolopyridine, $\mathrm{N}$-substituted-3-carboxamido- and other groups incorporate a coumarin moiety displaying new coumarin derivative structures which showed antibacterial [24-29] and antifungal [30] activities. Several novel coumarin analogs possess antimycobacterial activity [31-33]. Modification of the chemical structure of the coumarin parent skeleton showed unit enzyme inhibition in vitro and in vivo [34-37]. Coumarin also combines with sugar units to form C-glycosyl compounds. In this study, we report the characteristics of several chemicals including 4-hydroxycoumarin derivatives 1a-c, 5, and 7-hydroxycoumarin 9 and 3-carboxycoumarin derivatives 12. By using acid anhydrides, activated aziridines 6, benzotriazol-1-yloxtri-(pyrrolidinol)phosphonium hexafluorophosphate (PyBOP, 13), diisopropylethylethylamine (DIEA), dimethylformamide (DMF), alkylamines, and alkyldiamines to react with 3-carboxycoumarin, instead of dicyclohexylcarbodiimide (DCC) as a coupling reagent high yields of 3-carboxycoumarin amide dimers were obtained.

Microbiological trials using the minimal inhibitory concentration (MIC) on penicillin G, amikin and the new modified micro-plate antibiotic susceptibility test (MMAST) were carried out on different bacterial strains to test the activities of the new compounds [38].

\section{Results and Discussion}

Acylation of $1 \mathbf{a}-\mathbf{c}$ with acid anhydride in a suitable solvent at ca. $150{ }^{\circ} \mathrm{C}$ caused the substitution to produce $\mathbf{3 a}-\mathbf{c}, \mathbf{3} \mathbf{a}_{1}-\mathbf{c}_{1}$ and $\mathbf{3} \mathbf{a}_{2}-\mathbf{c}_{2}$. The acyl groups were removed via rearrangement to produce compounds $4 \mathbf{a}-\mathbf{c}, \mathbf{4} \mathbf{a}_{1}-\mathbf{c}_{1}$, and $\mathbf{4} \mathbf{a}_{2}-\mathbf{c}_{2}$ under heating conditions. 4-Acyloxycoumarins experienced a 
greater extent of rearrangement than 7-acyloxycoumarins. The effects might have been due to an electron deficiency inductive effect plus the different distances between position 7-acyloxy and the non-aromatic double-bond electron density at positions 3 and 4 of the 4-acyloxycoumarins. In this study, only the aliphatic acid anhydride acylation of 4-hydroxycoumarin caused rearrangements, while aromatic acid anhydrides failed to react. For 7-hydroxycoumarin, its acylation product was not observed, even when aliphatic or aromatic acid anhydrides with $\mathrm{NaOMe}$ in methanol were used. When 7-hydroxycoumarin treated with base will become more resonance anion and more difficult to react with anhydride by weak base $\mathrm{MeOH}$ and even by strong base $\mathrm{NaOMe}$. Therefore both of bases are unable to carry out the reaction. We also tried to use other diketone and amide compounds to react with the hydroxycoumarins, unfortunately, the expected acylation rearrangement did not occur. This might be explained by the greater number of methylene groups and the increase in the distance between the two $\mathrm{C}=\mathrm{O}$ bonds which makes it more difficult to attack the other carbonyl position. Synthesis of coumarin derivatives via the ring-opening reaction with activated aziridines has not been reported and characterized previously. The reaction of the coumarin anion with $N$-benzoyl- or $N$-sulfonylaziridines 6 yielded amidoethylated 7- or 4-hydroxycoumarins 7, 8, 9 and 10. The final results depend on the substitution of the $N$-acyl or $N$-sulfonyl groups on the acyl group, such as benzoyl and the coumarin anions will attack from an abnormal position to provide the major products 7d-f, 10n, and 10q. Only trace amounts of products are produced from normal ring-openings of aziridines. However, with the $N$-sulfonyl group, we obtained both products (in 4:1 ratio), but the main products resulted from normal ring-opening of the activated aziridines $7 \mathbf{h}, \mathbf{8 i}, \mathbf{8 j}, \mathbf{1 0 k}-\mathbf{l}$, and $11 \mathbf{k}$. It was assumed that compounds $7, \mathbf{8}, \mathbf{1 0}, \mathbf{1 1}$, and their analogues were formed by the nucleophilic attack of acylaziridines via an $\mathrm{S}_{\mathrm{N}}$ 2-like ring opening mechanism. The comparison of the proton NMR of the NH group in 7 and $\mathbf{8}$ revealed the cleavage of the ring position.

In our previous work [35], we reported that when PyBOP (13) was used as a coupling reagent to synthesize natural amide dimers, relatively high yields was obtained. The reaction did not perturb the formation of amide dimers even when a sugar moiety is attached to the parent compounds. In general, for the formation of amide or dimer chains, the reaction temperatures had a great influence on the structural conformation. From NMR spectroscopic analysis, the intermediate, coumarin-triazobenzene, displayed rearranged characteristics. We hypothesize that it might depend on the two factors of the solvent system introduced and the duration of the reaction. The reaction was carried out under mild conditions, by mixing the reagents with DMF at ca. $0{ }^{\circ} \mathrm{C}$, followed by the addition of DIEA. The resulting solution was allowed to warm to room temperature for 1-3 days, then alkyldimines were added dropwise to produce high yields of coumarin amide dimers.

All of the above synthetic products were further tested for their antibacterial effects. The MICs of the compounds tested against the reference strains are shown in Table 1. The antimicrobial tests performed on coumarin derivatives $3 \mathbf{c}, \mathbf{3} \mathbf{c}_{1}, \mathbf{4} \mathbf{a}_{2}, \mathbf{4 b}, \mathbf{4 c}$, and $\mathbf{7 f}$ confirmed the better activities of these compounds against Gram-positive rather than Gram-negative bacteria and some were especially active against Bacillus subtilis and Staphylococcus aureus. Compound $7 \mathbf{f}$ was the most potent of the tested compounds against $B$. subtilis, with an MIC value of $8 \mu \mathrm{g} / \mathrm{mL}$. Compounds $\mathbf{3 c}, \mathbf{3} \mathbf{c}_{\mathbf{1}}, \mathbf{4} \mathbf{a}_{2}, \mathbf{4 b}, \mathbf{4 c}$, and $\mathbf{7 d}$ only inhibit bacterial growth moderately, with lower MICs of 32, 16 , and $64 \mu \mathrm{g} / \mathrm{mL}$, respectively, when compared to penicillin G. The MICs of coumarin amide dimers 14-21 ranged from 128 to 256. Prior to these studies, the available information on coumarin-aziridins and the dimerization moiety of 
SAR indicated that molecular recognition involved specific receptor interactions. We propose that the various aziridines and dimer chain lengths might change the binding characteristics of ligands or the conformational direction to their respective receptors and, thereby, improve the biological activities.

Table 1. MICs of compounds 3, 4, 7, 8, 10, 11, and 14-21 against the reference strains.

\begin{tabular}{|c|c|c|c|c|}
\hline \multirow[b]{3}{*}{ Compds. } & \multicolumn{4}{|c|}{$\operatorname{MIC}(\mu \mathrm{g} / \mathrm{mL})^{a}$} \\
\hline & \multicolumn{2}{|c|}{$\operatorname{Gram}_{(+)}$bacteria $^{b}$} & \multicolumn{2}{|c|}{ Gram (-) bacteria } \\
\hline & B. $s$. & S. $a$. & E. $c$. & P. a. \\
\hline $3 \mathbf{a}$ & $>256$ & $>256$ & $>256$ & $>256$ \\
\hline $\mathbf{3} \mathbf{a}_{1}$ & $>256$ & $>256$ & $>256$ & $>256$ \\
\hline $3 \mathbf{a}_{2}$ & 128 & $>256$ & $>256$ & $>256$ \\
\hline $3 \mathbf{b}$ & 128 & $>256$ & 128 & $>256$ \\
\hline $3 \mathbf{b}_{1}$ & 128 & 256 & 256 & $>256$ \\
\hline $3 \mathbf{b}_{2}$ & $>256$ & $>256$ & $>256$ & $>256$ \\
\hline $3 c$ & 32 & 32 & $>256$ & $>256$ \\
\hline $3 \mathbf{c}_{1}$ & 32 & $>256$ & $>256$ & $>256$ \\
\hline $3 \mathbf{c}_{2}$ & $>256$ & $>256$ & $>256$ & $>256$ \\
\hline $4 a$ & 128 & $>256$ & $>256$ & $>256$ \\
\hline $4 a_{1}$ & $>256$ & $>256$ & $>256$ & $>256$ \\
\hline $4 a_{2}$ & 64 & $>256$ & $>256$ & $>256$ \\
\hline $4 b$ & 64 & 128 & 256 & $>256$ \\
\hline $4 b_{1}$ & $>256$ & $>256$ & $>256$ & $>256$ \\
\hline $4 b_{2}$ & 128 & $>256$ & $>256$ & $>256$ \\
\hline $4 c$ & 16 & 16 & 128 & $>256$ \\
\hline $4 c_{1}$ & $>256$ & $>256$ & $>256$ & $>256$ \\
\hline $4 c_{2}$ & 64 & 32 & $>256$ & $>256$ \\
\hline $7 d$ & 64 & 64 & $>256$ & $>256$ \\
\hline $7 e$ & $>256$ & $>256$ & $>256$ & $>256$ \\
\hline $7 f$ & 8 & 8 & $>256$ & $>256$ \\
\hline $7 \mathrm{~g}$ & $>256$ & $>256$ & $>256$ & $>256$ \\
\hline $7 \mathrm{~h}$ & $>256$ & $>256$ & $>256$ & $>256$ \\
\hline $8 \mathbf{i}$ & $>256$ & $>256$ & $>256$ & $>256$ \\
\hline $8 \mathbf{j}$ & $>256$ & $>256$ & $>256$ & $>256$ \\
\hline $10 \mathrm{k}$ & $>128$ & $>128$ & 128 & $>128$ \\
\hline 101 & $>128$ & $>128$ & $>128$ & $>128$ \\
\hline $10 \mathrm{~m}$ & $>128$ & $>128$ & 128 & $>128$ \\
\hline $10 n$ & $>128$ & $>128$ & $>128$ & $>128$ \\
\hline 100 & $>128$ & $>128$ & $>128$ & $>128$ \\
\hline $10 p$ & $>128$ & $>128$ & $>128$ & $>128$ \\
\hline $10 q$ & $>128$ & $>128$ & $>128$ & $>128$ \\
\hline $10 \mathrm{r}$ & $>128$ & $>128$ & $>128$ & $>128$ \\
\hline $11 \mathrm{k}$ & $>128$ & $>128$ & $>128$ & $>128$ \\
\hline 14 & $>128$ & $>128$ & $>128$ & $>128$ \\
\hline 15 & $>128$ & $>128$ & $>128$ & $>128$ \\
\hline 16 & $>128$ & $>128$ & $>128$ & $>128$ \\
\hline 17 & $>128$ & $>128$ & $>128$ & $>128$ \\
\hline
\end{tabular}


Table 1. Cont.

\begin{tabular}{|c|c|c|c|c|}
\hline \multirow[b]{3}{*}{ Compds. } & \multicolumn{4}{|c|}{ MIC $(\mu \mathrm{g} / \mathrm{mL})^{a}$} \\
\hline & \multicolumn{2}{|c|}{$\operatorname{Gram}_{(+)}$bacteria $^{b}$} & \multicolumn{2}{|c|}{ Gram (-) bacteria } \\
\hline & B. $s$. & S. $a$. & E. $c$. & P. a. \\
\hline 18 & $>128$ & $>128$ & $>128$ & $>128$ \\
\hline 19 & $>128$ & $>128$ & $>128$ & $>128$ \\
\hline 20 & $>128$ & $>128$ & $>128$ & $>128$ \\
\hline 21 & $>128$ & $>128$ & $>128$ & $>128$ \\
\hline PenicillinG $^{c}$ & 8 & 0.0625 & - & - \\
\hline Amikin & - & - & 1 & 0.125 \\
\hline
\end{tabular}

${ }^{a}$ MIC, minimal inhibitory concentration.$^{b}$ Bacteria: B. s., Bacillus subtilis (BCRC 10029); S. a., Staphylococcus aureus (BCRC 11863); E. c., Escherichia coli (BCRC 11758); P. a., Pseudomonas aeruginosa (BCRC 11733). ${ }^{c}$ Penicillin G potassium salt, Sigma p8721, lot 102K0483, 1,589 units/mg.

\subsection{Chemistry}

Regarding the synthetic route applied to 4-hydroxycoumarin derivatives, 4-hydroxycoumarin and its analogues 1a-c were used as starting materials to react with acid anhydrides, acetic anhydride, e.g., propionic anhydride, and benzoic anhydride, to produce the corresponding O-acyloxyl products 3a-c. It was observed that a proton on the hydroxyl group of coumarin was substituted by an acyl group when we elevated the temperature to ca. $150{ }^{\circ} \mathrm{C}$. Similar conditions were adopted to produce the $O$-acyloxyl and benzoyloxyl derivatives as the main reaction products. High yields were achieved when methyl groups were introduced at the 6 and 7 positions of the parent coumarin structure (Scheme 1).

Scheme 1. 4-Hydroxycoumarin reacted with acid anhydride.
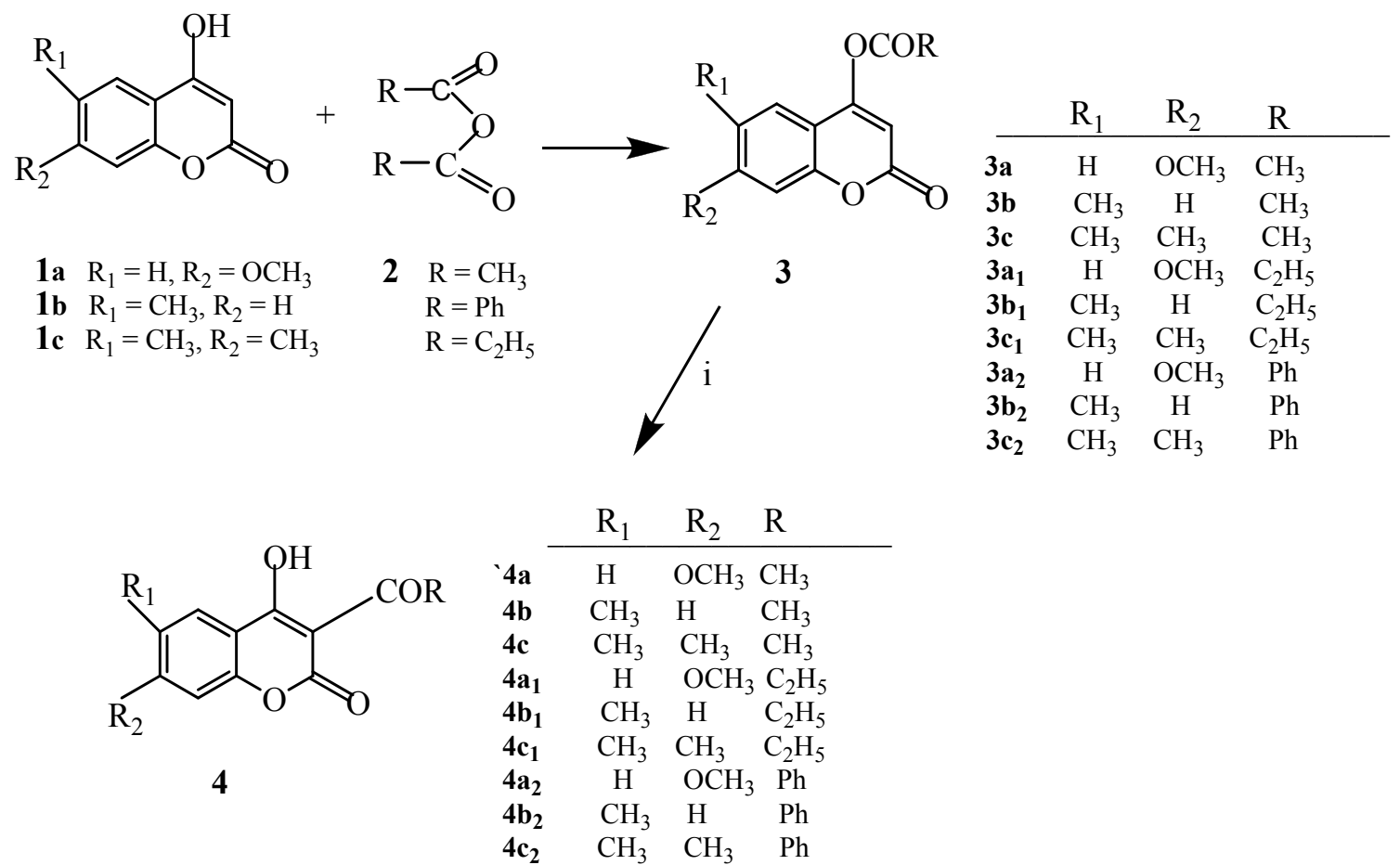

Reaction Conditions: i. reflux. 
The subsequent reaction involving heating over $170{ }^{\circ} \mathrm{C}$ in a sealed tube led to the rearrangement products $4 \mathbf{a}-\mathbf{c}$ in yields comparable to compounds 3a-c. Methyl group substitution produced greater yields of $52 \%-64 \%$. Excess acid anhydrides were finally removed by column chromatography on silica gel. Furthermore, 4-hydroxy- and 7-hydroxycoumarin derivatives were found to undergo ring-opening reactions with various activated aziridines (Schemes 2 and 3).

Scheme 2. 4-Hydroxycoumarin reacted with activated aziridines 6.

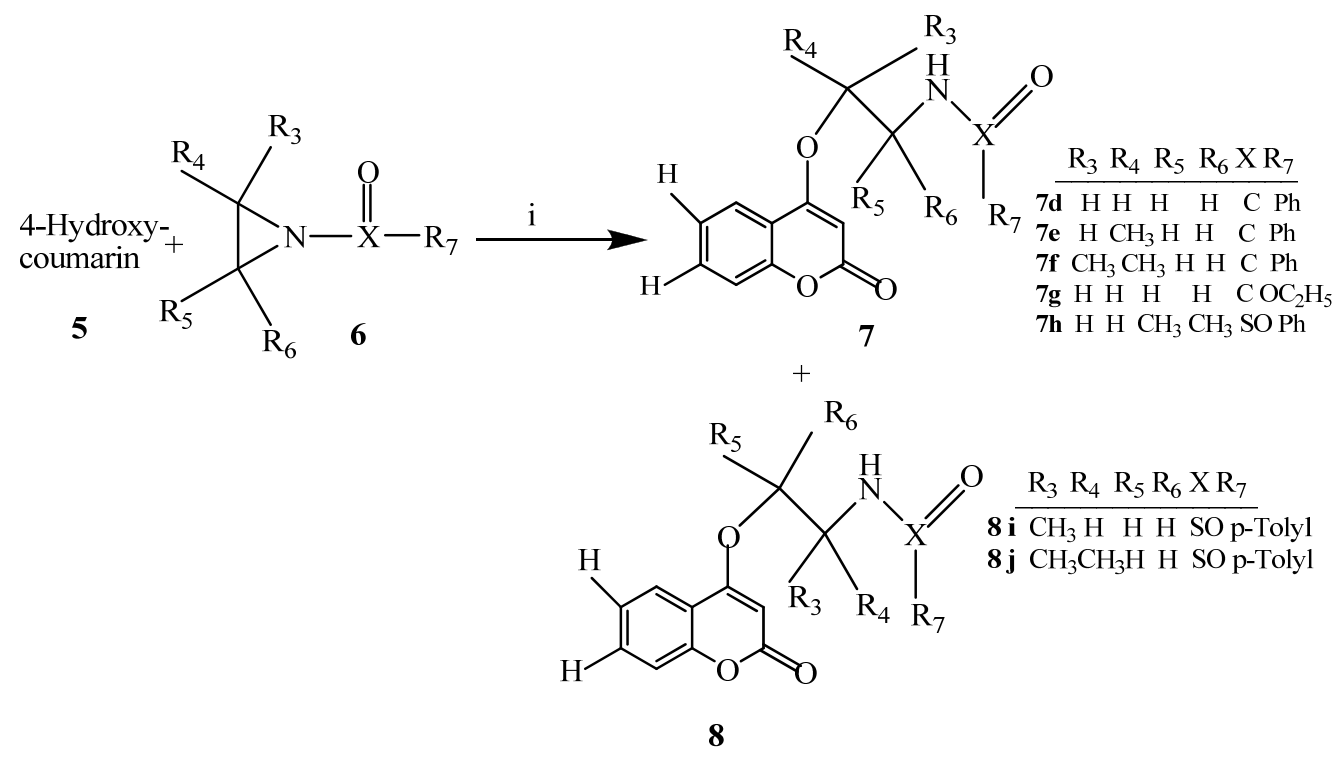

Reagents: i. $\mathrm{NaOCH}_{3} / \mathrm{THF}$.

Scheme 3. Reactions of 7-hydroxycoumarin with activatived aziridines 6.<smiles>O=c1ccc2ccc(O)cc2o1</smiles><smiles>[R][X](=O)N1C([R3])([R3])C1([R3])[2H]</smiles><smiles>[R]C(=O)NC([R9])([R3])Oc1ccc2ccc(=O)oc2c1</smiles><smiles>[R]C(=O)NC([R9])([R3])C([R3])([R])Oc1ccc2ccc(=O)oc2c1</smiles>

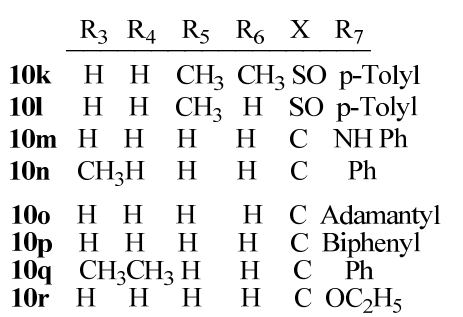

Reagents: i. $\mathrm{K}_{2} \mathrm{CO}_{3} /$ acetone. 
These new and convenient approaches to the synthesis of 4-hydroxy-, 7-hydroxycoumarins or other hydroxycoumarin derivatives were apparently caused by the nucleophilic attack on the activated aziridine rings. We used two hydroxycoumarins as starting materials in refluxing tetrahydrofuran (THF) and acetone in the presence of a base $\left(\mathrm{NaOCH}_{3}\right.$ or $\left.\mathrm{K}_{2} \mathrm{CO}_{3}\right)$ for 2-3 $\mathrm{h}$ to form "coumarin 5-O" and "coumarin 9-O" [the anions of 4-hydroxycoumarin (5) and 7-hydroxycoumarin (9)], and then reacted them with various activated aziridines. It was found that two isomers $\mathbf{7 , 8}$ or 10, 11 were produced from each hydroxycoumarin in yields of $28 \%-88 \%$. The main products generated from $N$-benzoylaziridines $(\mathrm{X}=\mathrm{C})$ were produced by abnormal regioselective ring-opening reactions producing $\mathbf{7 d}-\mathbf{g}, \mathbf{1 0 m}-\mathbf{n}$, and $\mathbf{1 0 q}$ with strongly preferred cleavage of the $\mathrm{N}-\mathrm{CH}_{2}$ bond. In the similar reactions with tolylaziridines $(\mathrm{X}=\mathrm{SO})$, a mixture of normal regioselectivity ring-opening products $\mathbf{7 h}$, $\mathbf{8 i}-\mathbf{j}, \mathbf{1 0 k}-\mathbf{l}$, and $11 \mathbf{k}$ were observed to predominate.

The syntheses of some coumarin dimers using Mn(III) or Fe(III) in the presence of a strong acid to obtain high yields were reported. We reacted coumarin acid 12 with diamines $(\mathrm{n}=3-12)$ in the presence of PyBOP, DIEA, and dimethylformamide at room temperature or $60{ }^{\circ} \mathrm{C}$ with stirring for $18 \mathrm{~h}$. The excess solvent, DIEA, and alkyldiamines were removed by column chromatography on silica gel to provide coumarin amide dimers 14-21 in excellent yields $(82 \%-87 \%)$. The products were recrystallized from ether and methanol (Scheme 4). The yields of dimers seem not to be affected by the bulky PyBOP reagent and essentially no steric hindrance between diamines and coumarins was observed. The chemical structures of these products were established using spectroscopic methods including IR, ${ }^{1} \mathrm{H}-,{ }^{13} \mathrm{C}-\mathrm{NMR}$, FAB-MS, HR-FAB-MS, and LC/MS/MS (ESI). The IR spectra of these amide dimers showed the $\mathrm{C}=\mathrm{O}$ absorption peaks around $1647-1665 \mathrm{~cm}^{-1}$. In the ${ }^{1} \mathrm{H}-\mathrm{NMR}$ (in $\mathrm{CDCl}_{3}$ ) the amide $\mathrm{N}-\mathrm{H}$ absorption appeared at $\delta 8.79-8.92 \mathrm{ppm}$ as a broad singlet. The ethylene amide dimers of coumarins revealed doublet of doublet signals at $\delta 3.47 \mathrm{ppm}\left(-\mathrm{NH}-\mathrm{CH}_{2}-\right) .{ }^{13} \mathrm{C}-\mathrm{NMR}$ showed the amide (NH-C) signal at $\delta 161.4-161.8 \mathrm{ppm}$ in the parent compounds.

Scheme 4. 3-Carboxycoumarin reactions with alkyldiamines.

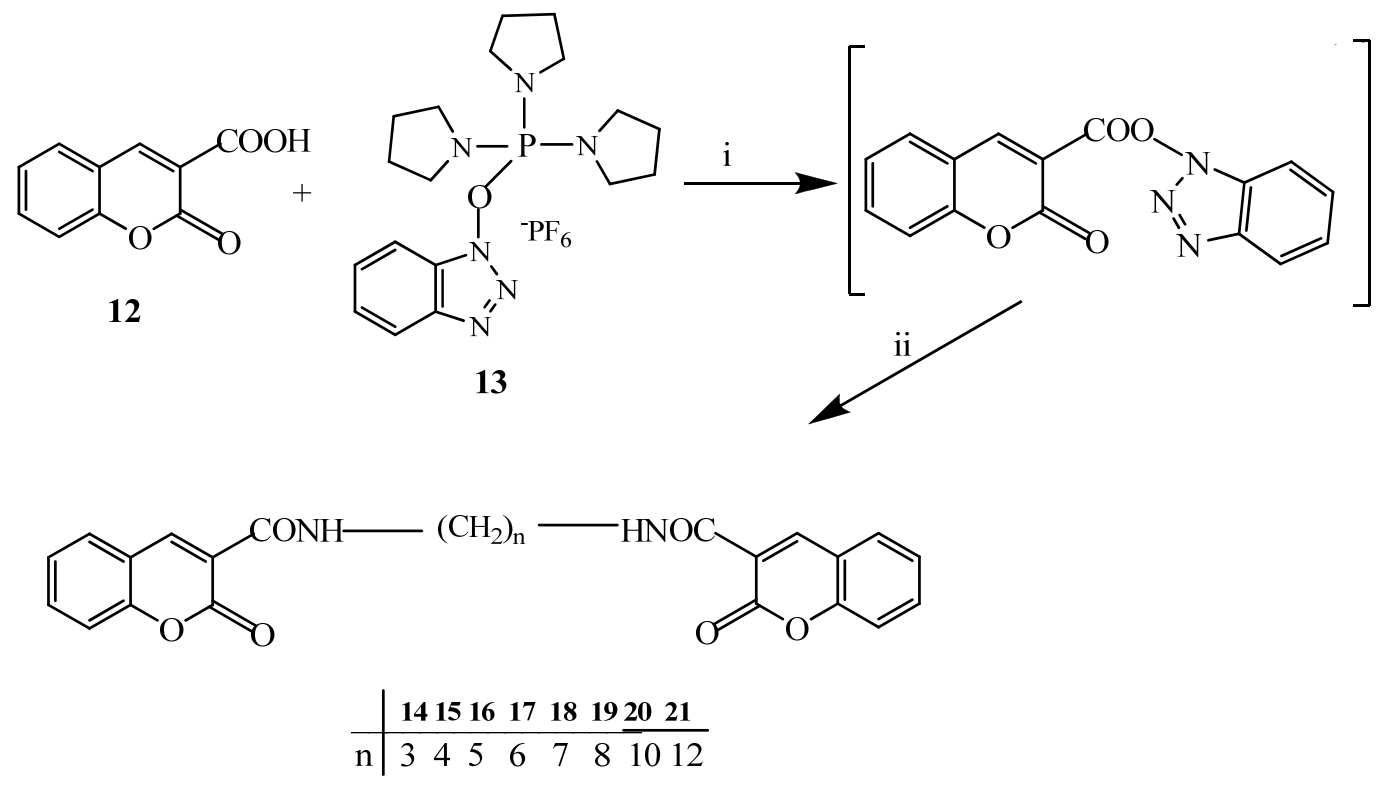

Reagents: i, DIEA/THF; ii, 3-coumaric acid/THF, alkyldiamine. 


\subsection{Antibacterial Activity Test}

Acyl coumarins 3a-4c, 4-hydroxy-, and 7-hydroxycoumarins 7-11 and coumaric amide dimers 14-21 were tested against reference strains of Bacillus subtilis (BCRC 10029), Staphylococcus aureus (BCRC 11863), Escherichia coli (BCRC 11758), and Pseudomonas aeruginosa (BCRC 11733) obtained from The Bioresources Collection \& Research Center (BCRC), Taiwan. Penicillin G potassium salt (CAS 113-98-4, USP grade) was used as a reference and purchased from Sigma-Aldrich (St. Louis, MO, USA). Bacteria were grown overnight in Müller-Hinton broth (Difco, Detroit, MI, USA) and trypticase soy broth (TSB, Oxoid, Basingstoke, Hampshire, UK).

The minimal inhibitory concentrations (MICs) of all synthesized compounds were determined using the reference method of broth dilution measurements. Each test compound and penicillin $G$ was dissolved in DMSO/EtOH/phosphate buffer or phosphate buffer before a serial two-fold dilution to the desired test concentration ranges. DMSO/EtOH/phosphate buffer and phosphate buffer were used for the solvent control test. The seed was cultured with trypticase soy broth containing $10^{7}$ colony forming units (cfu)/mL. Müller-Hinton broth was sterilized by autoclaving at $120{ }^{\circ} \mathrm{C}$ for $15 \mathrm{~min}$, and microorganism were suspended in 96-well microplate. The final concentration of microorganism in each well was $10^{5} \mathrm{cfu} / \mathrm{mL}$. Modified 96-well plates were used with a two-fold micro-dilution method of the MTT assay in Müller-Hinton broth. Microorganism suspensions containing $10^{5} \mathrm{cfu} / \mathrm{mL}$ were inoculated onto the 96-well microplates and mixed with the test compounds. The MIC was defined as the lowest concentration of test compounds, allowing no visible growth of test strain bacteria after incubation at $37{ }^{\circ} \mathrm{C}$ for $3 \mathrm{~h}$. Then SDS in $0.1 \mathrm{~N} \mathrm{HCl}$ was added. The absorbance was measured by ELISA reader (Bio-Tek Instruments, Microplate Autoreader, EL 311) at $595 \mathrm{~nm}$.

\section{Experimental}

\subsection{General}

The IR spectra were recorded on a Thermo Mattson IR300 and Nicolet 510 PET spectrometers. Optical rotations were measured with a JASCO p-1020 digital polarimeter. NMR spectra were recorded at $500\left({ }^{1} \mathrm{H}-\mathrm{NMR}\right)$ and $125 \mathrm{MHz}\left({ }^{13} \mathrm{C}-\mathrm{NMR}\right)$ on a Bruker DRX-500 spectrometer in $\mathrm{CDCl}_{3}$ or DMSO solution with respect to the corresponding solvent peak used as the internal standard. Mass spectra were measured on a Finnigan/Thermo Quest NAT 95XL, JEOL JMX-HX 110, JEOL JMSHX 110 FAB-MS, and LC/MS/MS Micromass Quattro II. The compounds were prepared according to similar procedures, and reactions took place in high-pressure tubes (Büchiglasuster, bursting disc, 0032). For the chromatographic analysis, Merck silica gel 60 was used. The chemical reagents used in the synthesis were purchased from Sigma-Aldrich and Merck. The crude products were purified by column chromatography and recrystallized using ether/methanol or $n$-hexane/methanol. Biological data were recorded on a Microplate Autoreader EL 311.

\subsection{Preparation of Acylcoumarins}

4-Hydroxycoumarin and its derivatives 1a-c were added to a high-pressure tube (Bursting disc, Büchiglasuster) containing of acid anydride 2. The solution was stirred for $2 \mathrm{~h}$ at $150{ }^{\circ} \mathrm{C}$. The dried 
mass was separated by column chromatography $(\mathrm{CHCl3} / \mathrm{EA} / \mathrm{n}$-hexane $=8: 1: 1)$ to give compounds 3a-c. Next the solution was stirred at $180{ }^{\circ} \mathrm{C}$ and purified by column chromatography to obtaine the rearranged compounds $\mathbf{4 a -}-\mathbf{c}$.

\subsection{Preparation of 4-hydroxy-, and 7-hydroxycoumarin Derivatives via Ring Opening of Activated} Aziridines

Synthesis of 4-hydroxy-, and 7-hydroxycoumarin derivatives with activated aziridines are shown in Schemes 2 and 3. Compound 5 was dissolved in dry acetone, $\mathrm{CH}_{3} \mathrm{ONa}$ and then added activated aziridine. The mixture was stirred at $130{ }^{\circ} \mathrm{C}$, and dry mass was purified by column chromatography $(\mathrm{CHCl} 3 / \mathrm{EA}=9: 1)$ for compounds 7 and $\mathbf{8}$. Compound 9 was dissolved in dry acetone then added $\mathrm{K}_{2} \mathrm{CO}_{3}$ with same procedure for compounds $\mathbf{1 0}$ and $\mathbf{1 1}$.

\subsection{Preparation of Coumarin Amide Dimers}

Synthesis of the desired amide dimer derivatives of coumarin acid with alkyldiamines is shown in scheme 4. The PyBOP coupling reagent was used to prepare a series of coumarin acid amide dimers under mild conditions. Compound $\mathbf{1 2}$ was dissolved in dry dimethylformamide (DMF) then added various alkyldiamines. When the mixtures were cooled PyBOP solution DMF and diisopropylethylamine (DIEA) was added. After the mixture was allowed to warm to room temperature and stirred for $18 \mathrm{~h}$ the residues were purified by column chromatography $\left(\mathrm{CHCl}_{3} /\right.$ acetone $\left.=10: 1\right)$ for compounds 14-21.

4-O-Acetyl-7-methoxycoumarin (3a). M.p. $131 \sim 134{ }^{\circ} \mathrm{C} .{ }^{1} \mathrm{H}-\mathrm{NMR}\left(\mathrm{CDCl}_{3}\right) \delta: 2.40(3 \mathrm{H}, \mathrm{s}), 3.86(3 \mathrm{H}, \mathrm{s})$, $6.82(1 \mathrm{H}, \mathrm{d}, J=2.1 \mathrm{~Hz}), 6.84(1 \mathrm{H}, \mathrm{dd}, J=7.6,2.1 \mathrm{~Hz}), 7.47(1 \mathrm{H}, \mathrm{d}, J=7.6 \mathrm{~Hz}), \mathrm{IR}\left(\mathrm{KBr}, \mathrm{cm}^{-1}\right) 1656$ $(\mathrm{C}=\mathrm{O}), 1721$ (lactone).

4-O-Acetyl-6-methylcoumarin (3b). M.p. $128-130{ }^{\circ} \mathrm{C} .{ }^{1} \mathrm{H}-\mathrm{NMR}\left(\mathrm{CDCl}_{3}\right) \delta: 2.45(3 \mathrm{H}, \mathrm{s}), 2.47(3 \mathrm{H}, \mathrm{s})$, $6.32(1 \mathrm{H}, \mathrm{s}), 7.26(1 \mathrm{H}, \mathrm{d}, J=7.5 \mathrm{~Hz}), 7.46(1 \mathrm{H}, \mathrm{dd}, J=7.5,2.1 \mathrm{~Hz}), \mathrm{IR}\left(\mathrm{KBr}, \mathrm{cm}^{-1}\right) 1645,1680(\mathrm{C}=\mathrm{O})$.

4-O-Acetyl-6,7-dimethylcoumarin (3c). M.p. $157-159{ }^{\circ} \mathrm{C} .{ }^{1} \mathrm{H}-\mathrm{NMR}\left(\mathrm{CDCl}_{3}\right)$ \&: $2.35(3 \mathrm{H}, \mathrm{s}), 2.36$ $(3 \mathrm{H}, \mathrm{s}), 2.42(3 \mathrm{H}, \mathrm{s}), 6.27(1 \mathrm{H}, \mathrm{s}), 7.13(1 \mathrm{H}, \mathrm{s}), 7.67(1 \mathrm{H}, \mathrm{s})$. IR $\left(\mathrm{KBr}, \mathrm{cm}^{-1}\right) 1657,1720(\mathrm{C}=\mathrm{O})$.

4-O-Propionyl-7-methoxycoumarin (3a- $)$. M.p. $176-177^{\circ} \mathrm{C} .{ }^{1} \mathrm{H}-\mathrm{NMR}\left(\mathrm{CDCl}_{3}\right) \delta: 1.53(3 \mathrm{H}, \mathrm{t}, J=7.6 \mathrm{~Hz})$, $2.45(2 \mathrm{H}, \mathrm{q}, J=7.6 \mathrm{~Hz}), 3.86(3 \mathrm{H}, \mathrm{s}), 6.50(1 \mathrm{H}, \mathrm{dd}, J=8.3,2.4 \mathrm{~Hz}), 7.69(1 \mathrm{H}, J=8.3 \mathrm{~Hz}) . \mathrm{IR}(\mathrm{KBr})$ $1645,1748(\mathrm{C}=\mathrm{O}) \mathrm{cm}^{-1}$.

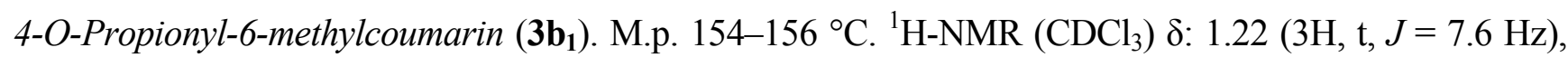
$2.43(3 \mathrm{H}, \mathrm{s}), 3.22(2 \mathrm{H}, \mathrm{q}, J=7.6 \mathrm{~Hz}), 7.04(1 \mathrm{H}, \mathrm{s}), 7.20(1 \mathrm{H}, \mathrm{d}, J=7.9 \mathrm{~Hz}), 7.47(1 \mathrm{H}, \mathrm{dd}, J=7.9,1.9 \mathrm{~Hz})$, $7.84(1 \mathrm{H}, \mathrm{s}) . \mathrm{IR}\left(\mathrm{KBr}, \mathrm{cm}^{-1}\right) 1634,1701(\mathrm{C}=\mathrm{O})$.

4-O-Propionyl-6,7-dimethylcoumarin (3c1). M.p. $167-168{ }^{\circ} \mathrm{C} .{ }^{1} \mathrm{H}-\mathrm{NMR}\left(\mathrm{CDCl}_{3}\right) \delta: 1.32(3 \mathrm{H}$, t, $J=7.5 \mathrm{~Hz}), 2.31(3 \mathrm{H}, \mathrm{s}), 2.35(3 \mathrm{H}, \mathrm{s}), 2.72(2 \mathrm{H}, \mathrm{q}, J=7.5 \mathrm{~Hz}), 6.41(1 \mathrm{H}, \mathrm{s}), 7.14(1 \mathrm{H}, \mathrm{s}), 7.30(1 \mathrm{H}, \mathrm{s})$. IR $\left(\mathrm{KBr}, \mathrm{cm}^{-1}\right)$ 1646, $1711(\mathrm{C}=\mathrm{O}) . \mathrm{MS} \mathrm{m} / \mathrm{z}$ (rel. int \%): $246(\mathrm{M})^{+}(14), 190(51), 148$ (78), 91 (20), 57 (100). 


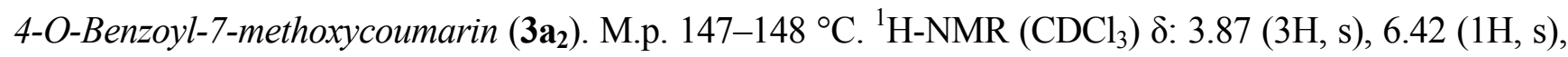
$6.84(1 \mathrm{H}, \mathrm{d}, J=2.2 \mathrm{~Hz}), 6.84(1 \mathrm{H}, \mathrm{dd}, J=7.5,2.2 \mathrm{~Hz}), 7.54(1 \mathrm{H}, \mathrm{d}, J=7.5 \mathrm{~Hz}), 7.54(2 \mathrm{H}, \mathrm{t}, J=7.5 \mathrm{~Hz})$, $7.68(1 \mathrm{H}, \mathrm{t}, J=7.5 \mathrm{~Hz}), 8.20(2 \mathrm{H}, \mathrm{d}, J=7.5 \mathrm{~Hz}) . \mathrm{IR}\left(\mathrm{KBr}, \mathrm{cm}^{-1}\right) 1640,1710(\mathrm{C}=\mathrm{O}) . \mathrm{MS} \mathrm{m} / \mathrm{z}($ rel. int \%): $296(\mathrm{M})^{+}(2), 105(1), 77(40), 51(20)$.

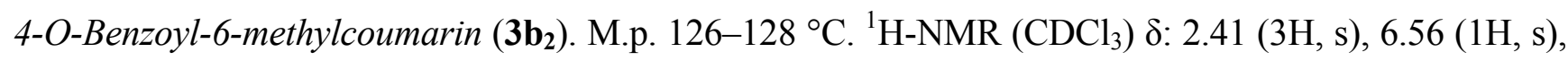
$7.29(1 \mathrm{H}, \mathrm{d}, J=8.4 \mathrm{~Hz}), 7.39(1 \mathrm{H}, \mathrm{dd}, J=8.4,2.1 \mathrm{~Hz}), 7.44(1 \mathrm{H}, \mathrm{d}, J=2.1 \mathrm{~Hz}), 7.58(2 \mathrm{H}, \mathrm{t}, J=7.7 \mathrm{~Hz})$, $7.72(1 \mathrm{H}, \mathrm{t}, J=7.7 \mathrm{~Hz}), 8.24(2 \mathrm{H}, \mathrm{d}, J=7.7 \mathrm{~Hz}) . \mathrm{IR}\left(\mathrm{KBr}, \mathrm{cm}^{-1}\right) 1645,1720(\mathrm{C}=\mathrm{O})$.

4-O-Benzoyl-6,7-dimethylcoumarin (3c $\left.\mathbf{c}_{2}\right)$. M.p. $163-164{ }^{\circ} \mathrm{C} .{ }^{1} \mathrm{H}-\mathrm{NMR}\left(\mathrm{CDCl}_{3}\right) \delta: 2.26(3 \mathrm{H}, \mathrm{d}, J=7.1 \mathrm{~Hz})$, $2.33(3 \mathrm{H}, \mathrm{d}, J=7.1 \mathrm{~Hz}), 6.46(1 \mathrm{H}, \mathrm{s}), 7.16(1 \mathrm{H}, \mathrm{s}), 7.35(1 \mathrm{H}, \mathrm{s}), 7.55(2 \mathrm{H}, \mathrm{t}, J=7.9 \mathrm{~Hz}), 7.69(1 \mathrm{H}, \mathrm{t}$, $J=7.9 \mathrm{~Hz}), 8.21(2 \mathrm{H}, \mathrm{d}, J=7.9 \mathrm{~Hz})$. IR $\left(\mathrm{KBr}, \mathrm{cm}^{-1}\right) 1665,1728(\mathrm{C}=\mathrm{O})$.

3-Acetyl-4-hydroxy-7-methoxycoumarin (4a). M.p. 194-196 ${ }^{\circ} \mathrm{C} .{ }^{1} \mathrm{H}-\mathrm{NMR}\left(\mathrm{CDCl}_{3}\right)$ \&: 2.73 (3H, s), $3.89(3 \mathrm{H}, \mathrm{s}), 6.72(1 \mathrm{H}, \mathrm{d}, J=2.1 \mathrm{~Hz}), 6.85(1 \mathrm{H}, \mathrm{dd}, J=8.9,2.1 \mathrm{~Hz}), 7.92(1 \mathrm{H}, \mathrm{d}, J=8.9 \mathrm{~Hz}) . \mathrm{IR}$ $\left(\mathrm{KBr}, \mathrm{cm}^{-1}\right)$ 1661, $1753(\mathrm{C}=\mathrm{O}), 3442(\mathrm{OH}) . \mathrm{LC} / \mathrm{MS} / \mathrm{MS}(\mathrm{ESI}) \mathrm{m} / z$, (rel. int. \%): 234.9(M) ${ }^{+}(20), 217.3$ (-OH, 100), 192.9 (-acetyl, 62), 151.1 (74).

3-Acetyl-4-hydroxy-6-methylcoumarin (4b). M.p. 156-159 ${ }^{\circ} \mathrm{C} .{ }^{1} \mathrm{H}-\mathrm{NMR}\left(\mathrm{CDCl}_{3}\right) \delta: 2.43(3 \mathrm{H}, \mathrm{s}), 2.78$ $(3 \mathrm{H}, \mathrm{s}), 7.19(1 \mathrm{H}, \mathrm{d}, J=8.4 \mathrm{~Hz}), 7.48(1 \mathrm{H}, \mathrm{dd}, J=8.4,1.5 \mathrm{~Hz}), 7.84(1 \mathrm{H}, \mathrm{s}) . \mathrm{IR}(\mathrm{KBr}) 1661,1753$ $(\mathrm{C}=\mathrm{O}), 3410(\mathrm{OH})$. LC/MS/MS (ESI) $m / z$, (rel. int. \%) $243.2(\mathrm{M}+\mathrm{Na})(80), 203.1(\mathrm{M}+\mathrm{Na}-\mathrm{OH}, 90), 135.1$ (100).

3-Acetyl-4-hydroxy-6, 7-dimethylcoumarin (4c). M.p. $168-170{ }^{\circ} \mathrm{C} .{ }^{1} \mathrm{H}-\mathrm{NMR}\left(\mathrm{CDCl}_{3}\right) \delta: 2.36(3 \mathrm{H}, \mathrm{s})$, $2.41(3 \mathrm{H}, \mathrm{s}), 2.79(3 \mathrm{H}, \mathrm{s}), 7.11(1 \mathrm{H}, \mathrm{s}), 7.50(1 \mathrm{H}, \mathrm{s}) . \mathrm{IR}\left(\mathrm{KBr}, \mathrm{cm}^{-1}\right)$ 1631, $1723(\mathrm{C}=\mathrm{O}), 3419(\mathrm{OH})$. LC/MS/MS (ESI) $m / z$, (rel. int. \%) $233.2(\mathrm{M}+\mathrm{H})(30), 215.1\left(\mathrm{M}+\mathrm{H}-\mathrm{H}_{2} \mathrm{O}\right),(100), 149.2(60)$.

3-Acetyl-4-hydroxy-7-methoxycoumarin (4a) $)$. M.p. $197-199{ }^{\circ} \mathrm{C} .{ }^{1} \mathrm{H}-\mathrm{NMR}\left(\mathrm{CDCl}_{3}\right) \delta: 1.32(3 \mathrm{H}, \mathrm{t}$, $J=7.6 \mathrm{~Hz}), 2.72(2 \mathrm{H}, \mathrm{q}, J=7.6 \mathrm{~Hz}), 3.86(3 \mathrm{H}, \mathrm{s}), 6.79(1 \mathrm{H}, \mathrm{d}, J=2.2 \mathrm{~Hz}), 6.90(1 \mathrm{H}, \mathrm{dd}, J=7.8,2.2 \mathrm{~Hz})$, $7.83(1 \mathrm{H}, \mathrm{d}, J=7.8 \mathrm{~Hz})$. IR $\left(\mathrm{KBr}, \mathrm{cm}^{-1}\right)$ 1653, $1763(\mathrm{C}=\mathrm{O}), 3438(\mathrm{OH})$. LC/MS/MS (ESI) $\mathrm{m} / z$, (rel. int. \%) $287.0(\mathrm{M}+\mathrm{K})(60), 272.1(\mathrm{M}+\mathrm{K}-\mathrm{CH}),(100), 257.3\left(\mathrm{M}+\mathrm{K}-\mathrm{OCH}_{3}\right)(33), 244.1\left(\mathrm{M}+\mathrm{K}-\mathrm{C}_{3} \mathrm{H}_{7}\right)$ (90).

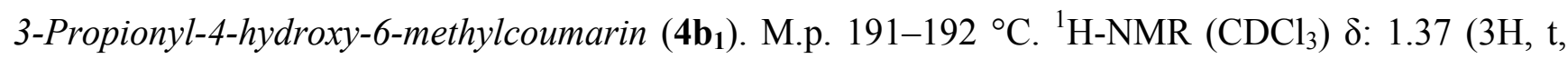
$J=7.5 \mathrm{~Hz}), 2.47(3 \mathrm{H}, \mathrm{s}), 2.77(2 \mathrm{H}, \mathrm{q}, J=7.1 \mathrm{~Hz}), 7.46(1 \mathrm{H}, \mathrm{dd}, J=7.1,2.1 \mathrm{~Hz}), 7.73(1 \mathrm{H}, \mathrm{s}), \mathrm{IR}$ $\left(\mathrm{KBr}, \mathrm{cm}^{-1}\right)$ 1652, $1759(\mathrm{C}=\mathrm{O})$. LC/MS/MS (ESI) $\mathrm{m} / z$, (rel. int. \%) $271.2(\mathrm{M}+\mathrm{K})^{+}(40), 256.0$ $\left(\mathrm{M}+\mathrm{K}-\mathrm{CH}_{3}\right)^{+}(60), 203.2(70), 135.0(100)$.

3-Propionyl-4-hydroxy-6,7-dimethylcoumarin (4c 1 ). M.p. 201-202 ${ }^{\circ} \mathrm{C} .{ }^{1} \mathrm{H}-\mathrm{NMR}\left(\mathrm{CDCl}_{3}\right) \delta: 1.34(3 \mathrm{H}$, $\mathrm{t}, J=7.6 \mathrm{~Hz}), 2.35(3 \mathrm{H}, \mathrm{s}), 2.37(3 \mathrm{H}, \mathrm{s}), 2.74(2 \mathrm{H}, \mathrm{q}, J=7.6 \mathrm{~Hz}), 7.12(1 \mathrm{H}, \mathrm{s}), 7.65(1 \mathrm{H}, \mathrm{s}) . \mathrm{IR}(\mathrm{KBr}$, $\left.\mathrm{cm}^{-1}\right)$ 1652, $1730(\mathrm{C}=\mathrm{O}), 3400(\mathrm{OH})$. LC/MS/MS (ESI) $\mathrm{m} / z$, (rel. int. \%) $285.1(\mathrm{M}+\mathrm{K})^{+}(80), 270.3$ $\left(\mathrm{M}+\mathrm{K}-\mathrm{CH}_{3}\right)^{+}, 255.1(23), 227.0$ (18), 217.2 (70), 149.1 (100), 105.0 (18). 
3-Benzoyl-4-hydroxy-7-methoxycoumarin (4a 2 ). M.p. $182-183{ }^{\circ} \mathrm{C} .{ }^{1} \mathrm{H}-\mathrm{NMR}\left(\mathrm{CDCl}_{3}\right) \delta: 3.89(3 \mathrm{H}, \mathrm{s})$, $6.86(1 \mathrm{H}, \mathrm{d}, J=2.3 \mathrm{~Hz}), 6.88(1 \mathrm{H}, \mathrm{dd}, J=7.7,2.3 \mathrm{~Hz}), 7.56(1 \mathrm{H}, \mathrm{t}, J=7.7 \mathrm{~Hz}), 7.54(2 \mathrm{H}, \mathrm{t}, J=7.8 \mathrm{~Hz})$, $7.72(1 \mathrm{H}, \mathrm{t}, J=7.8 \mathrm{~Hz}), 8.22(2 \mathrm{H}, \mathrm{d}, J=7.8 \mathrm{~Hz})$. IR $\left(\mathrm{KBr}, \mathrm{cm}^{-1}\right) 1650,1714(\mathrm{C}=\mathrm{O}), 3425(\mathrm{OH})$.

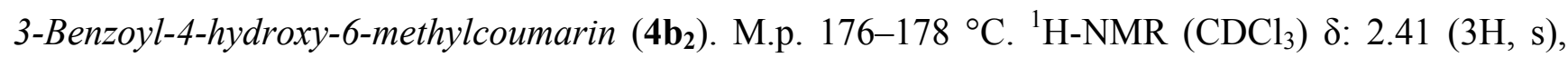
$7.29(1 \mathrm{H}, \mathrm{d}, J=7.6 \mathrm{~Hz}), 7.40(1 \mathrm{H}, \mathrm{dd}, J=7.6,1.8 \mathrm{~Hz}), 7.46(1 \mathrm{H}, \mathrm{s}), 7.58(2 \mathrm{H}, \mathrm{t}, J=7.7 \mathrm{~Hz}), 7.72(1 \mathrm{H}$, $\mathrm{t}, J=7.7 \mathrm{~Hz}), 8.24(2 \mathrm{H}, \mathrm{d}, J=7.7 \mathrm{~Hz})$. IR $\left(\mathrm{KBr}, \mathrm{cm}^{-1}\right)$ 1655, $1724(\mathrm{C}=\mathrm{O}), 3445(\mathrm{OH})$.

3-Benzoyl-4-hydroxy-6,7-dimethylcoumarin (4c $)$. M.p. 197-198 ${ }^{\circ} \mathrm{C} .{ }^{1} \mathrm{H}-\mathrm{NMR}\left(\mathrm{CDCl}_{3}\right) \delta: 2.30(3 \mathrm{H}, \mathrm{d}$, $J=7.1 \mathrm{~Hz}), 2.37(3 \mathrm{H}, \mathrm{d}, J=7.1 \mathrm{~Hz}), 7.16(1 \mathrm{H}, \mathrm{s}), 7.38(1 \mathrm{H}, \mathrm{s}), 7.57(2 \mathrm{H}, \mathrm{t}, J=7.7 \mathrm{~Hz}), 7.71(1 \mathrm{H}, \mathrm{t}$, $J=7.7 \mathrm{~Hz}), 8.24(2 \mathrm{H}, \mathrm{d}, J=7.7 \mathrm{~Hz})$. IR $\left(\mathrm{KBr}, \mathrm{cm}^{-1}\right) 1665,1728(\mathrm{C}=\mathrm{O}), 3480(\mathrm{OH})$.

4-(N-Benzoylamino)ethoxycoumarin (7d). M.p. $172-173{ }^{\circ} \mathrm{C} .{ }^{1} \mathrm{H}-\mathrm{NMR}\left(\mathrm{CDCl}_{3}\right) \delta: 4.01(2 \mathrm{H}, \mathrm{t}, J=5.2 \mathrm{~Hz})$, $4.32(2 \mathrm{H}, \mathrm{t}, J=5.2 \mathrm{~Hz}), 5.71(1 \mathrm{H}, \mathrm{s}), 6.53(1 \mathrm{H}, \mathrm{s}), 7.28(1 \mathrm{H}, \mathrm{d}, J=7.7 \mathrm{~Hz}), 7.32(1 \mathrm{H}, \mathrm{t}, J=7.7 \mathrm{~Hz})$. $7.43(2 \mathrm{H}, \mathrm{t}, J=8.2 \mathrm{~Hz}), 7.44(1 \mathrm{H}, \mathrm{t}, J=7.7 \mathrm{~Hz}), 7.52(1 \mathrm{H}, \mathrm{t}, J=8.2 \mathrm{~Hz}), 7.78(1 \mathrm{H}, \mathrm{d}, J=7.7 \mathrm{~Hz}), 7.83$ $(2 \mathrm{H}, \mathrm{d}, J=8.2 \mathrm{~Hz})$. IR (KBr, cm $\left.{ }^{-1}\right)$ 1653, $1730(\mathrm{C}=\mathrm{O}), 3223(\mathrm{NH}) . \mathrm{MS} m / z$ (rel. int. \%) 309 (2), 148 (91), 105 (100), 77 (95). HR-FAB-MS (EI, $80 \mathrm{eV}$ ) m/z, calculated for $\mathrm{C}_{18} \mathrm{H}_{15} \mathrm{NO}_{4}$ 309.1001, found 309.1000 .

4-[(N-Benzoylamino)-2-propoxyl] coumarin (7e). M.p. $193-194{ }^{\circ} \mathrm{C} .{ }^{1} \mathrm{H}-\mathrm{NMR}\left(\mathrm{CDCl}_{3}\right) \delta: 1.41(3 \mathrm{H}, \mathrm{d}$, $J=6.1 \mathrm{~Hz}), 3.79(1 \mathrm{H}, \mathrm{dd}, J=6.4,10.2 \mathrm{~Hz}), 3.94(1 \mathrm{H}, \mathrm{dd}, J=3.8,6.3,10.2 \mathrm{~Hz}), 4.88(1 \mathrm{H}, \mathrm{dd}$, $J=6.4,10.2 \mathrm{~Hz}), 5.78(1 \mathrm{H}, \mathrm{s}), 7.25(1 \mathrm{H}, \mathrm{d}, J=7.3 \mathrm{~Hz}), 7.27(1 \mathrm{H}, \mathrm{t}, J=7.3 \mathrm{~Hz}), 7.39(1 \mathrm{H}, \mathrm{t}$, $J=7.3 \mathrm{~Hz}), 7.42(2 \mathrm{H}, \mathrm{t}, J=7.8 \mathrm{~Hz}), 7.78(2 \mathrm{H}, \mathrm{d}, J=7.8 \mathrm{~Hz}) . \mathrm{IR}\left(\mathrm{KBr}, \mathrm{cm}^{-1}\right) 1635,1735(\mathrm{C}=\mathrm{O}), 3214$ (NH). MS m/z, (rel. int. \%) 323 (1), 174 (25), 148 (48), 59 (100).

4-[(N-Benzoylamino)-2-methyl-2-propoxy] coumarin (7f). M.p. $198-200{ }^{\circ} \mathrm{C} .{ }^{1} \mathrm{H}-\mathrm{NMR}\left(\mathrm{CDCl}_{3}\right) \delta: 1.38$ $(3 \mathrm{H}, \mathrm{s}), 3.88(2 \mathrm{H}, \mathrm{d}, J=6.3 \mathrm{~Hz}), 5.87(1 \mathrm{H}, \mathrm{s}), 6.52(1 \mathrm{H}, \mathrm{t}-\mathrm{like}), 7.27(1 \mathrm{H}, J=7.6 \mathrm{~Hz}), 7.29(1 \mathrm{H}, \mathrm{t}$, $J=7.6 \mathrm{~Hz}), 7.41(1 \mathrm{H}, \mathrm{t}, J=7.6 \mathrm{~Hz}), 7.44(2 \mathrm{H}, \mathrm{t}, J=7.9 \mathrm{~Hz}), 7.75(1 \mathrm{H}, \mathrm{d}, J=7.6 \mathrm{~Hz}), 7.78(1 \mathrm{H}, \mathrm{t}$, $J=7.9 \mathrm{~Hz}), 7.792 \mathrm{H}, \mathrm{d}, J=7.9 \mathrm{~Hz})$. IR $\left(\mathrm{KBr}, \mathrm{cm}^{-1}\right)$ 1648, $1742(\mathrm{C}=\mathrm{O}), 3300(\mathrm{NH}) . \mathrm{MS} \mathrm{m} / z$, (rel. int. \%) $337(\mathrm{M})^{+}$(1), 212 (21), 141 (25), 77 (100), 70 (90). HR-FAB-MS (EI, $80 \mathrm{eV}$ ) m/z, calculated for $\mathrm{C}_{2} \mathrm{OH}_{19} \mathrm{NO}_{4} 337.1314$, found 337.1322.

4-[(N-Ethylcarbamyl)ethyl]coumarin (7g). M.p. $123-124{ }^{\circ} \mathrm{C} .{ }^{1} \mathrm{H}-\mathrm{NMR}\left(\mathrm{CDCl}_{3}\right) \delta: 1.24(3 \mathrm{H}, \mathrm{t}, J=6.5 \mathrm{~Hz})$, $3.71(2 \mathrm{H}, \mathrm{d}, J=5.1 \mathrm{~Hz}), 4.14(2 \mathrm{H}, \mathrm{t}, J=5.1 \mathrm{~Hz}), 4.17(2 \mathrm{H}, \mathrm{q}, J=6.5 \mathrm{~Hz}), 5.03(1 \mathrm{H}, \mathrm{s}), 5.68(1 \mathrm{H}, \mathrm{s})$, $7.28(1 \mathrm{H}, \mathrm{d}, J=7.9 \mathrm{~Hz}), 7.31(1 \mathrm{H}, \mathrm{t}, J=7.9 \mathrm{~Hz}), 7.54(1 \mathrm{H}, \mathrm{t}, J=7.9 \mathrm{~Hz}), 7.80(1 \mathrm{H}, \mathrm{d}, J=7.9 \mathrm{~Hz}) . \mathrm{IR}$ $\left(\mathrm{KBr}, \mathrm{cm}^{-1}\right.$ ) MS m/z, (rel. int. \%) 277 (10), $116(80), 88$ (100).

4-[(N-Benzosulfonyl)-1,1-dimethylethyl] coumarin (7h). M.p. $169-171{ }^{\circ} \mathrm{C} .{ }^{1} \mathrm{H}-\mathrm{NMR}\left(\mathrm{CDCl}_{3}\right) \delta: 1.61$ $(6 \mathrm{H}, \mathrm{s}), 3.31(2 \mathrm{H}, \mathrm{d}, J=6.8 \mathrm{~Hz}), 5.72(1 \mathrm{H}, \mathrm{s}), 7.23-7.29(2 \mathrm{H}, \mathrm{dd}, J=8.1,8.2 \mathrm{~Hz}), 7.54(3 \mathrm{H}, \mathrm{dd}$, $J=1.3,7.4 \mathrm{~Hz}), 7.62(2 \mathrm{H}, \mathrm{ddd}, J=1.2,7.4,7.8 \mathrm{~Hz}), 7.86(2 \mathrm{H}$, dd-like, $J=1.1,7.2 \mathrm{~Hz}) . \mathrm{IR}(\mathrm{KBr}$, $\left.\mathrm{cm}^{-1}\right)$ 1638, $1692(\mathrm{C}=\mathrm{O}), 3200(\mathrm{NH})$. HR-FAB-MS (EI, $\left.80 \mathrm{eV}\right) \mathrm{m} / z$, calculated for $\mathrm{C}_{19} \mathrm{H}_{19} \mathrm{NO}_{5} \mathrm{~S}$ 373.0984, found 373.0986 . 
4-[(N-p-Tolylsulfonyl)-2-methylethyl] coumarin (8i). M.p. $154-156{ }^{\circ} \mathrm{C} .{ }^{1} \mathrm{H}-\mathrm{NMR}\left(\mathrm{CDCl}_{3}\right) \delta: 1.28(3 \mathrm{H}$, $\mathrm{d}, J=6.8 \mathrm{~Hz}), 2.39(3 \mathrm{H}, \mathrm{s}), 3.83(1 \mathrm{H}, \mathrm{m}), 3.96(2 \mathrm{H}, \mathrm{d}, J=3.8 \mathrm{~Hz}), 4.93(1 \mathrm{H}, \mathrm{d}, J=7.7 \mathrm{~Hz}), 5.48(1 \mathrm{H}, \mathrm{s})$, $7.21(1 \mathrm{H}, \mathrm{d}, J=7.6 \mathrm{~Hz}), 7.23(1 \mathrm{H}, \mathrm{t}, J=7.6 \mathrm{~Hz}), 7.29(2 \mathrm{H}, \mathrm{d}, J=8.2 \mathrm{~Hz}), 7.53(1 \mathrm{H}, \mathrm{t}, J=7.6 \mathrm{~Hz})$, $7.65(1 \mathrm{H}, \mathrm{d}, J=7.6 \mathrm{~Hz}), 7.72(2 \mathrm{H}, \mathrm{d}, J=8.2 \mathrm{~Hz}) . \mathrm{IR}\left(\mathrm{KBr}, \mathrm{cm}^{-1}\right) 1620,1693(\mathrm{C}=\mathrm{O}), 3172(\mathrm{NH}) . \mathrm{MS}$ $\mathrm{m} / z$, (rel. int. \%) 373 (10), 218 (25), 155 (46), 91 (100). HR-FAB-MS (EI, $80 \mathrm{eV)} \mathrm{m} / \mathrm{z}$, calculated for $\mathrm{C}_{19} \mathrm{H}_{19} \mathrm{NO}_{5} \mathrm{~S} 373.0984$, found 373.0986.

4-[(N-p-Tolylsulfonyl)-1,1-dimetylethyl] coumarin (8j). M.p. $187-190{ }^{\circ} \mathrm{C} .{ }^{1} \mathrm{H}-\mathrm{NMR}\left(\mathrm{CDCl}_{3}\right) \delta: 1.43$ $(3 \mathrm{H}, \mathrm{s}), 2.23(3 \mathrm{H}, \mathrm{s}), 3.89(2 \mathrm{H}, \mathrm{s}), 4.97(1 \mathrm{H}, \mathrm{s}), 5.85(1 \mathrm{H}, \mathrm{s}), 7.07(1 \mathrm{H}, \mathrm{d}, J=7.3 \mathrm{~Hz}), 7.28(1 \mathrm{H}, \mathrm{t}$, $J=7.3 \mathrm{~Hz}), 7.53(1 \mathrm{H}, \mathrm{t}, J=7.3 \mathrm{~Hz}), 7.65(2 \mathrm{H}, \mathrm{d}, J=7.5 \mathrm{~Hz}), 7.68(1 \mathrm{H}, \mathrm{d}, J=7.3 \mathrm{~Hz}), 7.73(2 \mathrm{H}, \mathrm{d}$, $J=7.5 \mathrm{~Hz})$. IR $\left(\mathrm{KBr}, \mathrm{cm}^{-1}\right)$ 1620, $1683(\mathrm{C}=\mathrm{O}), 3425(\mathrm{NH}) . \mathrm{MS} m / z$, (rel. int. \%) $387(\mathrm{M})^{+}(2), 212$ (25), 155 (30), 91 (100), 70 (70).

7-[(N-p-Tosyl)-2,2-dimethylethyloxy]coumarin (10k). M.p. $220-221{ }^{\circ} \mathrm{C} .{ }^{1} \mathrm{H}-\mathrm{NMR}\left(\mathrm{CDCl}_{3}\right) \delta: 1.36$ $(6 \mathrm{H}, \mathrm{s}), 2.45(3 \mathrm{H}, \mathrm{s}), 3.76(2 \mathrm{H}, \mathrm{s}), 4.91(1 \mathrm{H}, \mathrm{s}), 6.72(1 \mathrm{H}, \mathrm{d}, J=9.5 \mathrm{~Hz}), 6.62(1 \mathrm{H}, \mathrm{bs}), 6.76(1 \mathrm{H}, \mathrm{dd}$, $J=8.5,1.8 \mathrm{~Hz}), 7.18(2 \mathrm{H}, \mathrm{d}, J=7.9 \mathrm{~Hz}), 7.36(1 \mathrm{H}, \mathrm{d}, J=7.9 \mathrm{~Hz}), 7.63(1 \mathrm{H}, \mathrm{d}, J=9.5 \mathrm{~Hz}), 7.74$ $(2 \mathrm{H}, \mathrm{d}, J=8.0 \mathrm{~Hz})$. IR $\left(\mathrm{KBr}, \mathrm{cm}^{-1}\right) 1692(\mathrm{C}=\mathrm{O}), 3406(\mathrm{NH})$.

7-[(N-p-Tosyl)-2-methylethyloxy] coumarin (101). M.p. $110-111{ }^{\circ} \mathrm{C} .{ }^{1} \mathrm{H}-\mathrm{NMR}\left(\mathrm{CDCl}_{3}\right) \delta: 1.15(3 \mathrm{H}, \mathrm{s})$, $2.26(3 \mathrm{H}, \mathrm{s}), 3.62(1 \mathrm{H}, \mathrm{t}-\mathrm{like}, J=5.5 \mathrm{~Hz}), 3.73(1 \mathrm{H}, \mathrm{dd}, J=5.1,9.3 \mathrm{~Hz}), 3.81(1 \mathrm{H}, \mathrm{dd}, J=4.9,9.2 \mathrm{~Hz})$, $5.87(1 \mathrm{H}, \mathrm{d}, J=7.6 \mathrm{~Hz}), 6.12(1 \mathrm{H}, \mathrm{d}, J=9.2 \mathrm{~Hz}), 6.50(1 \mathrm{H}, \mathrm{bs}), 6.58(1 \mathrm{H}, \mathrm{d}, J=8.3 \mathrm{~Hz}), 7.13(2 \mathrm{H}, \mathrm{d}$, $J=7.7 \mathrm{~Hz}), 7.21(1 \mathrm{H}, \mathrm{d}, J=8.5 \mathrm{~Hz}), 7.56(1 \mathrm{H}, \mathrm{d}, J=9.5 \mathrm{~Hz}), 7.67(2 \mathrm{H}, \mathrm{d}, J=8.0 \mathrm{~Hz}) . \mathrm{IR}\left(\mathrm{KBr}, \mathrm{cm}^{-1}\right)$ $1718(\mathrm{C}=\mathrm{O}), 3421(\mathrm{NH})$.

7-[(N-Phenylaminylcarboxamido)ethyloxy]coumarin (10m). M.p. $164-165{ }^{\circ} \mathrm{C} .{ }^{1} \mathrm{H}-\mathrm{NMR}\left(\mathrm{CDCl}_{3}\right) \delta$ : $3.53(2 \mathrm{H}, \mathrm{t}, J=5.5 \mathrm{~Hz}), 4.07(2 \mathrm{H}, \mathrm{t}, J=5.3 \mathrm{~Hz}), 6.14(1 \mathrm{H}, \mathrm{d}, J=9.5 \mathrm{~Hz}), 6.24(1 \mathrm{H}, \mathrm{t}, J=5.6 \mathrm{~Hz}), 6.78$ $(1 \mathrm{H}, \mathrm{d}, J=2.3 \mathrm{~Hz}), 6.82(1 \mathrm{H}, \mathrm{dd}, J=2.8,8.6 \mathrm{~Hz}), 6.83(1 \mathrm{H}, \mathrm{ddd}, J=1.7,2.7,6.9 \mathrm{~Hz}), 7.13(2 \mathrm{H}, \mathrm{dd}$, $J=2.3,8.0 \mathrm{~Hz}), 7.30(2 \mathrm{H}, \mathrm{d}, J=8.0 \mathrm{~Hz}), 7.39(1 \mathrm{H}, \mathrm{d}, J=8.6 \mathrm{~Hz}), 7.68(1 \mathrm{H}, \mathrm{d}, J=8.1 \mathrm{~Hz}), 8.23$ $(1 \mathrm{H}, \mathrm{s}) . \mathrm{IR}\left(\mathrm{KBr}, \mathrm{cm}^{-1}\right)$ 1660, $1701(\mathrm{C}=\mathrm{O}), 3312(\mathrm{NH})$.

7-[(N-Benzoyl)-1-methylethyloxy] coumarin (10n). M.p. $135-136{ }^{\circ} \mathrm{C} .{ }^{1} \mathrm{H}-\mathrm{NMR}\left(\mathrm{CDCl}_{3}\right) \delta: 1.45(3 \mathrm{H}, \mathrm{d}$, $J=6.8 \mathrm{~Hz}), 4.15(2 \mathrm{H}, \mathrm{ddd}, J=4.5,9.3,12.4 \mathrm{~Hz}), 4.65(1 \mathrm{H}, \mathrm{dd}, J=3.5,7.1 \mathrm{~Hz}), 6.25(1 \mathrm{H}, \mathrm{d}, J=9.5 \mathrm{~Hz})$, $6.85(1 \mathrm{H}, \mathrm{d}, J=2.2 \mathrm{~Hz}), 6.89(1 \mathrm{H}, \mathrm{dd}, J=7.8,2.3 \mathrm{~Hz}), 7.38(1 \mathrm{H}, \mathrm{d}, J=8.6 \mathrm{~Hz}), 7.44(2 \mathrm{H}, \mathrm{dd}, J=7.8$, $2.1 \mathrm{~Hz}), 7.50(1 \mathrm{H}, \mathrm{d}, J=7.3 \mathrm{~Hz}), 7.62(1 \mathrm{H}, \mathrm{d}, J=9.5 \mathrm{~Hz}), 7.77(2 \mathrm{H}, \mathrm{d}, J=7.5 \mathrm{~Hz}) . \mathrm{IR}\left(\mathrm{KBr}, \mathrm{cm}^{-1}\right)$ 1662, $1708(\mathrm{C}=\mathrm{O}), 3330(\mathrm{NH})$.

7-[(2-Adamantanecarboxamido)ethyloxy] coumarin (10o). Oil. ${ }^{1} \mathrm{H}-\mathrm{NMR}\left(\mathrm{CDCl}_{3}\right) \delta: 1.11(3 \mathrm{H}, \mathrm{s}), 1.72$ $(6 \mathrm{H}, \mathrm{dd}, J=12.3,26.9 \mathrm{~Hz}), 1.86(6 \mathrm{H}, \mathrm{d}, J=2.4 \mathrm{~Hz}), 2.05(3 \mathrm{H}, \mathrm{s}), 3.69(2 \mathrm{H}, \mathrm{dd}, J=5.5,10.8 \mathrm{~Hz}), 4.10$ $(2 \mathrm{H}, \mathrm{t}, J=5.1 \mathrm{~Hz}), 6.03(1 \mathrm{H}, \mathrm{s}), 6.26(1 \mathrm{H}, \mathrm{d}, J=9.5 \mathrm{~Hz}) .6 .82(1 \mathrm{H}, \mathrm{d}, J=2.2 \mathrm{~Hz}), 6.85(1 \mathrm{H}, \mathrm{dd}$, $J=8.6,2.4 \mathrm{~Hz}), 7.38(1 \mathrm{H}, \mathrm{d}, J=8.5 \mathrm{~Hz}), 7.63(1 \mathrm{H}, \mathrm{d}, J=9.5 \mathrm{~Hz}) . \mathrm{IR}\left(\mathrm{KBr}, \mathrm{cm}^{-1}\right) 1663,1705(\mathrm{C}=\mathrm{O})$, $3282(\mathrm{NH})$.

7-[(N-p-Phenylbenzoyl)-ethyloxy] coumarin (10p). M.p. 216-217 ${ }^{\circ} \mathrm{C} .{ }^{1} \mathrm{H}-\mathrm{NMR}\left(\mathrm{CDCl}_{3}\right) \delta: 3.95(2 \mathrm{H}$, $\mathrm{dd}, J=5.5,10.8 \mathrm{~Hz}), 4.24(2 \mathrm{H}, \mathrm{t}, J=5.1 \mathrm{~Hz}), 6.86(1 \mathrm{H}, \mathrm{d}, J=2.3 \mathrm{~Hz}), 6.88(1 \mathrm{H}, \mathrm{dd}, J=8.4,2.3 \mathrm{~Hz})$, 
$7.39(2 \mathrm{H}, \mathrm{d}, J=8.4 \mathrm{~Hz}), 7.46(2 \mathrm{H}, \mathrm{t}, J=7.6 \mathrm{~Hz}), 7.61(2 \mathrm{H}, \mathrm{t}, J=4.5 \mathrm{~Hz}), 7.63(1 \mathrm{H}, \mathrm{d}, J=9.5 \mathrm{~Hz})$, $7.67(2 \mathrm{H}, \mathrm{d}, J=8.3 \mathrm{~Hz}), 7.87(2 \mathrm{H}, \mathrm{d}, 8.3 \mathrm{~Hz}) . \mathrm{IR}\left(\mathrm{KBr}, \mathrm{cm}^{-1}\right)$ 1656, $1697(\mathrm{C}=\mathrm{O}), 3356(\mathrm{NH})$.

7-[(N-Benzoyl)-1,1-dimethylethyloxy] coumarin (10q). M.p. $104-105{ }^{\circ} \mathrm{C} .{ }^{1} \mathrm{H}-\mathrm{NMR}\left(\mathrm{CDCl}_{3}\right) \delta: 1.40$ $(6 \mathrm{H}, \mathrm{s}), 3.71(2 \mathrm{H}, \mathrm{d}, J=6.0 \mathrm{~Hz}), 6.27(1 \mathrm{H}, \mathrm{d}, J=9.5 \mathrm{~Hz}), 6.76(1 \mathrm{H}, \mathrm{d}, J=4.2 \mathrm{~Hz}), 6.88(1 \mathrm{H}, \mathrm{d}$, $J=2.2 \mathrm{~Hz}), 6.89(1 \mathrm{H}, \mathrm{dd}, J=8.3,2.2 \mathrm{~Hz}), 7.36(1 \mathrm{H}, \mathrm{d}, J=8.4 \mathrm{~Hz}), 7.43(2 \mathrm{H}, \mathrm{t}, J=7.5 \mathrm{~Hz}), 7.49$ $(1 \mathrm{H}, \mathrm{t}, J=7.3 \mathrm{~Hz}), 7.63(1 \mathrm{H}, \mathrm{d}, J=9.5 \mathrm{~Hz}), 7.81(2 \mathrm{H}, \mathrm{d}, J=7.4 \mathrm{~Hz}) . \mathrm{IR}\left(\mathrm{KBr}, \mathrm{cm}^{-1}\right) 1651,1692$ $(\mathrm{C}=\mathrm{O}), 3366(\mathrm{NH})$.

7-[(N-Ethylcarbamyl)ethyloxy] coumarin (10r). M.p. $115-116{ }^{\circ} \mathrm{C} .{ }^{1} \mathrm{H}-\mathrm{NMR}\left(\mathrm{CDCl}_{3}\right) \delta: 1.25(3 \mathrm{H}, \mathrm{t}$, $J=6.8 \mathrm{~Hz}), 3.62(2 \mathrm{H}, \mathrm{d}, J=5.1 \mathrm{~Hz}), 4.09(1 \mathrm{H}, \mathrm{t}, J=5.0 \mathrm{~Hz}), 4.14(1 \mathrm{H}, \mathrm{t}, J=6.8 \mathrm{~Hz}), 5.10(1 \mathrm{H}, \mathrm{bs})$, $6.26(1 \mathrm{H}, \mathrm{d}, J=9.6 \mathrm{~Hz}), 6.80(1 \mathrm{H}, \mathrm{d}, J=1.8 \mathrm{~Hz}), 6.84(1 \mathrm{H}, \mathrm{dd}, J=8.6,2.2 \mathrm{~Hz}), 7.38(1 \mathrm{H}, \mathrm{d}, J=8.6 \mathrm{~Hz})$, $7.63(1 \mathrm{H}, \mathrm{d}, J=9.5 \mathrm{~Hz})$. IR $\left(\mathrm{KBr}, \mathrm{cm}^{-1}\right) 1677,1733(\mathrm{C}=\mathrm{O}), 3292(\mathrm{NH})$.

7-[(N-p-Tosyl)-1,1-dimethylethyloxy] coumarin (11k). M.p. $177-178{ }^{\circ} \mathrm{C} .{ }^{1} \mathrm{H}-\mathrm{NMR}\left(\mathrm{CDCl}_{3}\right) \delta: 1.36$ $(6 \mathrm{H}, \mathrm{s}), 2.45(3 \mathrm{H}, \mathrm{s}), 3.12(2 \mathrm{H}, \mathrm{d}, J=6.4 \mathrm{~Hz}), 4.88(1 \mathrm{H}, \mathrm{t}, J=5.8 \mathrm{~Hz}), 6.32(1 \mathrm{H}, \mathrm{d}, J=9.5 \mathrm{~Hz}), 6.80$ $(2 \mathrm{H}, \mathrm{d}, J=7.3 \mathrm{~Hz}), 7.35(3 \mathrm{H}, \mathrm{dd}, J=7.4,5.5 \mathrm{~Hz}), 7.64(1 \mathrm{H}, \mathrm{d}, J=9.5 \mathrm{~Hz}), 7.76(2 \mathrm{H}, \mathrm{d}, J=8.1 \mathrm{~Hz})$. IR $\left(\mathrm{KBr}, \mathrm{cm}^{-1}\right) 1721(\mathrm{C}=\mathrm{O}), 3416(\mathrm{NH})$

Bis(3-coumarin) propylenediamide (14). M.p. $264-265{ }^{\circ} \mathrm{C} .{ }^{1} \mathrm{H}-\mathrm{NMR}\left(\mathrm{CDCl}_{3}\right) \delta: 1.98(2 \mathrm{H}, \mathrm{dd}, J=6.5$, $13.3 \mathrm{~Hz}), 3.58(2 \mathrm{H}, \mathrm{dd}, J=6.4,12.8 \mathrm{~Hz}), 7.38(2 \mathrm{H}, \mathrm{dd}, J=7.9,7.6 \mathrm{~Hz}), 7.67(2 \mathrm{H}, \mathrm{ddd}, J=1.1,7.4$, $8.4 \mathrm{~Hz}), 8.92(1 \mathrm{H}, \mathrm{bs}), 9.01(1 \mathrm{H}, \mathrm{s}) .{ }^{13} \mathrm{C}-\mathrm{NMR} \delta 29.61\left(\mathrm{CH}_{2} \mathrm{CN}\right), 37.40\left(2 \times \mathrm{CCH}_{2} \mathrm{~N}\right), 116.62\left(\mathrm{C}-4,4^{\prime}\right)$, 118.55 (C-8,8'), 118.68 (C-5,5'), 125.22 (C-6,6'), 129.77 (C-7,7'), 133.94 (C-9,9'), 148.31 (C-3,3'), $154.46\left(\mathrm{C}-10,10^{\prime}\right), 161.38(\mathrm{OCN}), 161.82(\mathrm{O}=\mathrm{CO})$. IR (KBr, cm $\left.{ }^{-1}\right)$ 1658, $1705(\mathrm{C}=\mathrm{O}), 3341(\mathrm{NH})$. HR-FAB-MS (EI, $80 \mathrm{eV}$ ) $\mathrm{m} / z$, calculated for $\mathrm{C}_{23} \mathrm{H}_{18} \mathrm{~N}_{2} \mathrm{O}_{6} 418.1165$, found 418.1163 .

Bis(3-coumarin)butamethylenediamide (15). M.p. $250-251{ }^{\circ} \mathrm{C} .{ }^{1} \mathrm{H}-\mathrm{NMR}\left(\mathrm{CDCl}_{3}\right) \delta: 1.75(2 \mathrm{H}, \mathrm{t}$, $J=2.8 \mathrm{~Hz}), 3.52(2 \mathrm{H}, \mathrm{d}, J=5.8 \mathrm{~Hz}), 7.39(2 \mathrm{H}, \mathrm{dd}, J=8.8,7.5 \mathrm{~Hz}), 7.68(2 \mathrm{H}, \mathrm{ddd}, J=8.8,7.7,1.4 \mathrm{~Hz})$, $8.86(1 \mathrm{H}, \mathrm{bs}, \mathrm{NH}), 8.91(1 \mathrm{H}, \mathrm{s}, \mathrm{H}-4) .{ }^{13} \mathrm{C}-\mathrm{NMR} \delta: 27.02\left(2 \times \mathrm{NCCH}_{2}\right), 39.47\left(2 \times \mathrm{NCH}_{2} \mathrm{C}\right), 116.61\left(\mathrm{C}-4,4^{\prime}\right)$, $118.51\left(\mathrm{C}-8,8^{\prime}\right), 118.67$ (C-5,5'), 125.25 (C-6,6'), 129.79 (C-7,7'). 133.96 (C-9,9'), 148.31(C-3,3'), $154.41\left(\mathrm{C}-10,10^{\prime}\right), 161.41(\mathrm{OCN}), 161.48(\mathrm{O}=\mathrm{CO})$. IR $\left(\mathrm{KBr}, \mathrm{cm}^{-1}\right)$ 1658, $1710(\mathrm{C}=\mathrm{O}), 3337(\mathrm{NH})$. HR-FAB-MS (EI, $80 \mathrm{eV}$ ) $\mathrm{m} / z$, calculated for $\mathrm{C}_{24} \mathrm{H}_{20} \mathrm{~N}_{2} \mathrm{O}_{6} 432.1321$, found 432.1471 .

Bis(3-coumarin)pentamethylenediamide (16). M.p. $221-222{ }^{\circ} \mathrm{C} .{ }^{1} \mathrm{H}-\mathrm{NMR}\left(\mathrm{CDCl}_{3}\right) \delta: 1.52(2 \mathrm{H}$, ddd, $J=6.9,8.4,12.1 \mathrm{~Hz}), 1.70(4 \mathrm{H}, \mathrm{dd}, J=7.3,14.7 \mathrm{~Hz}), 3.49\left(4 \mathrm{H}, \mathrm{dd}, J=13.1,6.9 \mathrm{~Hz}, 2 \mathrm{~N}-\mathrm{CH}_{2}\right), 7.38$ $(4 \mathrm{H}, \mathrm{dd}, J=7.7,8.8 \mathrm{~Hz}), 7.67(4 \mathrm{H}, \mathrm{dd}, J=7.7,8.4 \mathrm{~Hz}), 8.82(2 \mathrm{H}, \mathrm{bs}, \mathrm{NH}), 8.90\left(2 \mathrm{H}, \mathrm{s}, \mathrm{H}-4,4^{\prime}\right)$. ${ }^{13} \mathrm{C}-\mathrm{NMR} \delta: 24.38\left(\mathrm{NCCCH}_{2}\right), 29.08\left(2 \times \mathrm{NCCH}_{2}\right), 39.67\left(2 \times \mathrm{CH}_{2}\right), 116.61\left(\mathrm{C}-4,4^{\prime}\right), 118.63\left(\mathrm{C}-8,8^{\prime}\right)$, 118.72 (C-5,5'), 125.22 (C-6,6'), 129.77 (C-7,7'), 133.88 (C-9,9'), 148.19 (C-3,3'), 154.43 (C-10,10'), 161.45 (OCN), 161.47 (OCO). IR ( $\mathrm{KBr}, \mathrm{cm}^{-1}$ ) 1654, $1702(\mathrm{C}=\mathrm{O})$. HR-FAB-MS (EI, $\left.80 \mathrm{eV}\right) \mathrm{m} / z$, calculated for $\mathrm{C}_{25} \mathrm{H}_{22} \mathrm{~N}_{2} \mathrm{O}_{6} 446.1478$, found 446.1477 .

Bis(3-coumarin)hexamethylenediamide (17). M.p. $212-213{ }^{\circ} \mathrm{C} .{ }^{1} \mathrm{H}-\mathrm{NMR}\left(\mathrm{CDCl}_{3}\right) \delta: 1.46(4 \mathrm{H}, \mathrm{t}-\mathrm{like}$, $J=7.1,12.2 \mathrm{~Hz}), 1.66(4 \mathrm{H}, \mathrm{t}$-like $J=6.7,13.5 \mathrm{~Hz}), 3.47(4 \mathrm{H}, \mathrm{dd}, J=6.8,13.1 \mathrm{~Hz}), 7.38(4 \mathrm{H}, \mathrm{dd}$, $J=7.6,8.5 \mathrm{~Hz}), 7.68(4 \mathrm{H}, \mathrm{dd}, J=7.2,8.5 \mathrm{~Hz}), 8.81(2 \mathrm{H}, \mathrm{bs}, \mathrm{NH}), 8.91\left(2 \mathrm{H}, \mathrm{s}, \mathrm{H}-4,4{ }^{\prime}\right) .{ }^{13} \mathrm{C}-\mathrm{NMR} \delta$ : 
$26.71\left(2 \times \mathrm{NCCCH}_{2}\right), 29.31\left(2 \times \mathrm{NCCH}_{2}\right), 39.80\left(2 \times \mathrm{NCH}_{2}\right), 116.61\left(\mathrm{C}-4,4{ }^{\prime}\right), 118.65\left(\mathrm{C}-8,8^{\prime}\right), 118.72$ (C-5,5'), 125.22 (C-6,6'), 129.76 (C-7,7'), 133.88 (C-9,9'), 148.17 (C-3,3'), 154.42 (C-10,10'), 161.41 (OCN),161.48 (OCO). IR (KBr, cm ${ }^{-1}$ ) 1668, 1712 (C=O), 3341 (NH). HR-FAB-MS (EI, 80 eV) m/z, calculated for $\mathrm{C}_{26} \mathrm{H}_{24} \mathrm{~N}_{2} \mathrm{O}_{6} 460.1634$, found 460.1640 .

Bis(3-coumarin)heptamethylenediamide (18). M.p. $198-199{ }^{\circ} \mathrm{C} .{ }^{1} \mathrm{H}-\mathrm{NMR}\left(\mathrm{CDCl}_{3}\right) \delta: 1.42(6 \mathrm{H}, \mathrm{s}$, $\left.\mathrm{NCC}\left(\mathrm{CH}_{2}\right)_{3}\right), 1.64\left(4 \mathrm{H}, \mathrm{t}\right.$-like, $\left.J=6.2,12.9 \mathrm{~Hz}, \mathrm{NC}\left(\mathrm{CH}_{2}\right)_{2}\right), 3.47\left(4 \mathrm{H}, \mathrm{dd}, J=7.0,13.1 \mathrm{~Hz}, \mathrm{~N}\left(\mathrm{CH}_{2}\right)_{2}\right)$, 7.38 (4H, dd, $\left.J=7.5,9.2 \mathrm{~Hz}, \mathrm{H}-6,6^{\prime}, 8,8^{\prime}\right), 7.66$ (4H, dd, $\left.J=1.1,7.7,9.0 \mathrm{~Hz}, \mathrm{H}-5,5^{\prime}, 7,7^{\prime}\right), 8.80$ (2H, bs, $2 \times \mathrm{NH}), 8.91\left(2 \mathrm{H}, \mathrm{s}, \mathrm{H}-4,4{ }^{\prime}\right) .{ }^{13} \mathrm{C}-\mathrm{NMR} \delta: 26.90\left(\mathrm{NCCCCH}_{2}\right), 28.94\left(\mathrm{NCCCH}_{2}\right), 29.32\left(\mathrm{NCCH}_{2}\right)$, $39.85\left(\mathrm{NCH}_{2}\right), 116.0\left(\mathrm{C}-4,4^{\prime}\right), 118.65\left(\mathrm{C}-8,8^{\prime}\right), 118.72$ (C-5,5'), $125.21\left(\mathrm{C}-6,6^{\prime}\right), 129.75\left(\mathrm{C}-7,7^{\prime}\right), 133.87$ (C-9,9'), 148.16 (C-3,3'), 154.41 (C-10,10'), 161.37 (CON), 161.47 (COO). IR (KBr, cm $\left.{ }^{-1}\right)$ 1662, 1704 $(\mathrm{C}=\mathrm{O}), 3368(\mathrm{NH}) . \mathrm{MS}$ (rel.int. \%) $475.384\left(\mathrm{M}^{+}+\mathrm{H}\right)$ (40), 191.041 (100), 173.029 (80). HR-FAB-MS (Ei, $80 \mathrm{eV}$ ) $m / z$, calculated for $\mathrm{C}_{27} \mathrm{H}_{26} \mathrm{~N}_{2} \mathrm{O}_{6} 474.1791$, found 474.2761 .

Bis(3-coumarin)octamethylenediamide (19). M.p. $199-200{ }^{\circ} \mathrm{C} .{ }^{1} \mathrm{H}-\mathrm{NMR}\left(\mathrm{CDCl}_{3}\right) \delta: 1.31$ (8H, t-like, $J=3.8,7.1 \mathrm{~Hz}), 1.63(4 \mathrm{H}, \mathrm{dd}, J=7.1,14.0 \mathrm{~Hz}), 3.46\left(4 \mathrm{H}, \mathrm{dd}, J=7.0,13.1 \mathrm{~Hz}, 2 \times \mathrm{NCH}_{2}\right), 7.38(4 \mathrm{H}$, $\left.\mathrm{dt}, J=1.4,7.5,8.4 \mathrm{~Hz}, \mathrm{H}-6,6^{\prime}, 8,8^{\prime}\right), 7.67$ (4H, dddd, $\left.J=1.0,1.2,8.6,8.9 \mathrm{~Hz}, \mathrm{H}-5,5^{\prime}, 7,7^{\prime}\right), 8.80$ (2H, bs, $2 \times \mathrm{NH}), 8.91\left(2 \mathrm{H}, \mathrm{s}, \mathrm{H}-4,4{ }^{\prime}\right) .{ }^{13} \mathrm{C}-\mathrm{NMR} \delta: 26.94\left(\mathrm{NCCCCH}_{2}\right), 29.16\left(\mathrm{NCCCH}_{2}\right), 29.36(\mathrm{NCCH} 2)$, $39.90\left(\mathrm{NCH}_{2}\right), 116.61\left(\mathrm{C}-4,4^{\prime}\right), 118.67\left(\mathrm{C}-8,8^{\prime}\right), 118.72\left(\mathrm{C}-5,5^{\prime}\right), 12522\left(\mathrm{C}-6,6^{\prime}\right), 129.76\left(\mathrm{C}-7,7^{\prime}\right)$, $133.88\left(\mathrm{C}-9,9^{\prime}\right), 148.14$ (C-3,3'), 154.42 (C-10,10'), 161.37 (OCN), 161.49 (OCO). IR (KBr, cm $\left.{ }^{-1}\right)$ 1665, $1710(\mathrm{C}=\mathrm{O}), 3342(\mathrm{NH})$. HR-FAB-MS (EI, $80 \mathrm{eV}) \mathrm{m} / z$, calculated for $\mathrm{C}_{28} \mathrm{H}_{28} \mathrm{~N}_{2} \mathrm{O}_{6} 488.1947$, found 488.1951 .

Bis(3-coumarin)decamethylenediamide (20). M.p. 203-204 ${ }^{\circ} \mathrm{C} .{ }^{1} \mathrm{H}-\mathrm{NMR}\left(\mathrm{CDCl}_{3}\right) \delta$ : 1.37 (12H, t-like, $J=5.9,8.9 \mathrm{~Hz}), 1.63(4 \mathrm{H}, \mathrm{dt}, J=7.4,14.3 \mathrm{~Hz}), 3.46\left(4 \mathrm{H}, \mathrm{dd}, J=6.9,13.2 \mathrm{~Hz}, \mathrm{NCH}_{2}\right), 7.38(4 \mathrm{H}$, $\left.J=7.5,8.1 \mathrm{~Hz}, \mathrm{H}-6,6^{\prime}, 8,8^{\prime}\right), 7.67$ (4H, dd, $\left.J=7.7,8.6 \mathrm{~Hz}, \mathrm{H}-5,5^{\prime} 7,7^{\prime}\right), 8.80$ (2H, bs, NH), 8.91 (2H, s, H-4,4'). ${ }^{13} \mathrm{C}-\mathrm{NMR} \delta: 27.01,29.26,29.38,29.43,39.96\left(\mathrm{NCH}_{2}\right), 116.61\left(\mathrm{C}-4,4^{\prime}\right), 118.68\left(\mathrm{C}-8,8^{\prime}\right)$, $118.73\left(\mathrm{C}-5,5^{\prime}\right), 125.22$ (C-6,6'), 129.76 (C-7,7'), 133.88 (C-9,9'), 148.14 (C-3,3'), 154.42 (C-10,10'), 161.39 (OCN), 161.49 (OCO). IR ( KBr, cm $\left.{ }^{-1}\right)$ 1647, $1688(\mathrm{C}=\mathrm{O}), 3310(\mathrm{NH})$. LCMS 517.305 $\left(\mathrm{M}^{+}+\mathrm{H}\right)$, HR-FAB-MS (EI, 80eV) $\mathrm{m} / z$, calculated for $\mathrm{C}_{30} \mathrm{H}_{32} \mathrm{~N}_{2} \mathrm{O}_{6} 512.2260$, found 516.2051.

Bis(3-coumarin)dodecamethylenediamide (21). M.p. $172-173{ }^{\circ} \mathrm{C} .{ }^{1} \mathrm{H}-\mathrm{NMR}\left(\mathrm{CDCl}_{3}\right) \delta$ : $1.36(16 \mathrm{H}$, ddd, $J=6.6,7.5,13.5 \mathrm{~Hz}), 1.63(4 \mathrm{H}, \mathrm{dt}, J=7.5,14.4 \mathrm{~Hz}), 3.45\left(4 \mathrm{H}, \mathrm{dd}, J=7.0,13.1 \mathrm{~Hz}, 2 \times \mathrm{NCH}_{2}\right)$, 7.38 (4H, dt, $\left.J=7.5,8.4 \mathrm{~Hz}, \mathrm{H}-6,6^{\prime}, 8,8^{\prime}\right), 7.68$ (4H, dddd, $\left.J=1.3,5.7,7.6,8.7 \mathrm{~Hz}, \mathrm{H}-5,5^{\prime}, 7,7^{\prime}\right), 8.79$ $(2 \mathrm{H}, \mathrm{bs}, \mathrm{NH}), 8.91\left(2 \mathrm{H}, \mathrm{s}, \mathrm{H}-4,4{ }^{\prime}\right) .{ }^{13} \mathrm{C}-\mathrm{NMR} \delta: 27.03,29.30,29.38,29.51,29.54,39.96\left(\mathrm{NCH}_{2}\right)$, $116.61\left(\mathrm{C}-4,4^{\prime}\right), 118.68\left(\mathrm{C}-8,8^{\prime}\right), 118.73\left(\mathrm{C}-5,5^{\prime}\right), 125.22$ (C-6,6'), $129.76\left(\mathrm{C}-7,7^{\prime}\right), 133.88\left(\mathrm{C}-9,9^{\prime}\right)$, 148.14 (C-3,3'), 154.42 (C-10,10'), 161.39 (OCN), 161.49 (OCO). IR ( $\left.\mathrm{KBr}, \mathrm{cm}^{-1}\right)$ 1664, $1707(\mathrm{C}=\mathrm{O})$, $3362(\mathrm{NH})$. HR-FAB-MS (EI, 80eV) $m / z$, calculated for $\mathrm{C}_{32} \mathrm{H}_{36} \mathrm{~N}_{2} \mathrm{O}_{6}$ 544.2573, found 544.2572.

\section{Conclusions}

Synthesis of coumarin derivatives via the ring-opening reaction with activated aziridines has not been reported previously. The reaction of the coumarin anion with $N$-benzoyl- or $N$-sulfonylaziridines 
6 yielded amidoethylated 7- or 4-hydroxycoumarins 7, 8,9 and 10. The final results depend on the substitution of the $N$-acyl or $N$-sulfonyl groups on the acyl group, so the benzoyl and the coumarin anions will attack from an abnormal position to provide the major products $\mathbf{7 d - f}, \mathbf{1 0 n}$, and $\mathbf{1 0 q}$. The main products resulted from normal ring-opening of the activated aziridines $7 \mathbf{h}, \mathbf{8 i}, \mathbf{8 j}, \mathbf{1 0 k}-\mathbf{l}$, and $\mathbf{1 1} \mathbf{k}$. It was assumed that compounds $7, \mathbf{8 , 1 0}, \mathbf{1 1}$, and their analogues were formed by the nucleophilic attack of acylaziridines via an $\mathrm{S}_{\mathrm{N}}$ 2-like ring opening mechanism. In our previous work, when PyBOP (13) used as a coupling reagent to synthesize natural amide dimers, relatively high yields were obtained. In general, for the formation of amide or dimer chains, the reaction temperature had a great influence on the structural conformation. From NMR spectroscopic analysis, the intermediate, coumarin-triazobenzene, displayed rearrangement characteristics. The antimicrobial tests performed on coumarin derivatives $\mathbf{3 c}, \mathbf{3} \mathbf{c}_{1}, \mathbf{4} \mathbf{a}_{2}, \mathbf{4 b}, \mathbf{4} \mathbf{c}$, and $\mathbf{7 f}$ confirmed the better potential activities of these compounds against Gram-positive rather than Gram-negative bacteria. Compound 7f was the most potent of these tested compounds against $B$. subtilis, with a MIC value of $8 \mu \mathrm{g} / \mathrm{mL}$, while the coumarin amide dimers 14-21 displayed lower antibacterial activities (the MICs are $>128$ to 256).

\section{Acknowledgments}

We are grateful to Emil T. Lin, Department of Biopharmaceutical Sciences, School of Pharmacy, University of California at San Francisco (UCSF) for the LC/MS/MS determination. We also thank Fan-Ing Lin Hsu for financial support of this research work.

\section{References}

1. Dastan, D.; Salehi, P.; Gohari, A.R.; Zimmermann, S.; Kaiser, M.; Hamburger, M.; Khavasi, H.R.; Ebrahimi, S.N. Disesquiterpene and sesquiterpene coumarins from Ferula pseudalliacea, and determination of their absolute configurations. Phytochemistry 2012, 78, 170-178.

2. Verma, P.; Pal, H. Intriguing H-aggregate and H-dimer formation of coumarin-481 dye in aqueous solution as evidenced from photophysical studies. J. Phys. Chem. A 2012, 116, 4473-4484.

3. Stoianov, S.V.; Robinson, H.D. Two-Photon Activated Two-Photon Fluorescence and Binding of Azidocoumarin in a Gelatin Matrix. J. Fluoresc. 2012, 22, 1291-1300.

4. Manevich, Y.; Held, K.D.; Biaglow, J.E. Coumarin-3-carboxylic acid as a detector for hydroxyl radicals generated chemically and by gamma radiation. Radiat. Res. 1997, 148, 580-591.

5. Xing, Z.; Fu, Y.; Zhou, J.; Zhu, C.; Cheng, Y. Coumarin-based chiral fluorescence sensor incorporating a thiourea unit for highly enantioselective recognition of N-Boc-protected proline. Org. Biomol. Chem. 2012, 10, 4024-4028.

6. Barooah, N.; Mohanty, J.; Pal, H.; Bhasikuttan, A.C. Non-covalent interactions of coumarin dyes with cucurbit[7]uril macrocycle: modulation of ICT to TICT state conversion. Org. Biomol. Chem. 2012, 10, 5055-5062.

7. Chung, J.W.; Lee, K.; Neikirk, C.; Nelson, C.M.; Priestley, R.D. Photoresponsive coumarinstabilized polymeric nanoparticles as a detectable drug carrier. Small 2012, 8, 1693-1700.

8. Li, H.; Xiao, Y.; Niu, J.; Chen, X.; Ping, Q. Preparation of a cationic nanoemulsome for intratumoral drug delivery and its enhancing effect on cellular uptake in vitro. J. Nanosci. Nanotechnol. 2011, 11, 8547-8555. 
9. Dahl, O.E. New oral antithrombotics: Focus on dabigatran, an oral, reversible direct thrombin inhibitor for the prevention and treatment of venous and arterial thromboembolic disorders. Vasc. Health Risk Manag. 2012, 8, 45-57.

10. Penning-Van Beest, F.J.; Koerselman, J.; Herings, R.M. Risk of major bleeding during concomitant use of antibiotic drugs and coumarin anticoagulants. J. Thromb. Haemost. 2008, 6, 284-290.

11. Kontogiorgis, C.; Hadjipavlou-Litina, D. Biological evaluation of several coumarin derivatives designed possible anti-inflammatory/antioxidant agents. J. Enzyme Inhib. Med. Chem. 2003, 18, $63-69$.

12. Liu, Z.Q.; Yu, W.; Liu, Z.L. Antioxidative and prooxidative effects of coumarin derivatives on free radical initiated and photosensitized peroxidation of human low-density lipoprotein. Chem. Phys. Lipids 1999, 103, 125-135.

13. Hamdi, N.; Passarelli, V.; Romerosa, A. Synthesis, spectroscopy and electrochemistry of new 4-(4-acetyl-5-substituted-4,5-dihydro-1,3,4-oxadiazol-2-yl)methoxy)- $2 H$-chromen-2-ones as a novel class of potential antibacterial and antioxidant derivatives. C. R. Chim. 2011, 14, 548-555.

14. Hamdi, N.; Bouabdallah, F.; Romerosa, A. Expedious synthesis for $\alpha, \beta$ unsaturated coumarin derivatives using boran chelates: A novel class of potential antibacterial and antioxidant agents. C. R. Chim. 2010, 13, 1261-1268.

15. Hamdi, N.; Fischmeister, C.; Puerta, M.C.; Valerga, P. A rapid access to new coumarinyl chalcone and substituted chromen[4,3-c] pyrazol-4(1H)-ones and their antibacterial and DPPH radical scavenging activities. Med. Chem. Res. 2011, 20, 522-530.

16. Finn, G.J.; Kenealy, E.; Creaven, B.S.; Egan, D.A. In vitro cytotoxic potential and mechanism of action of selected coumarins, using human renal cell lines. Cancer Lett. 2002, 183, 61-68.

17. Jimenez-Orozco, F.A.; Lopez-Gonzalez, J.S.; Nieto-Rodriguez, A. Decrease of cyclin D1 in the human lung adenocarcinoma cell line A-427 by 7-hydroxycoumarin. Lung Cancer 2001, 34, 185-194.

18. Weber, U.S.; Steffen, B.; Siegers, C.P. Antitumor-activities of coumarin, 7-hydroxy-coumarin and its glucuronide in several human tumor cell lines. Res. Commun. Mol. Pathol. Pharmacol. 1998, 99, 193-206.

19. Singh, R.K.; Lange, T.S.; Kim, K.K.; Brard, L. A coumarin derivatives (RKS262) inhibits cell-cycle progression, causes pro-apoptotic signaling and cytotoxicity in ovarian cancer cells. Invest. New Drugs 2011, 29, 63-72.

20. Sabry, N.M.; Mohamed, H.M.; Khattab, E.S.; Motlaq, S.S.; El-Agrody, A.M. Synthesis of $4 H$-chromene, coumarin, $12 H$-chromeno[2,3-d]pyrimidine derivatives and some of their antimicrobial and cytotoxicity activities. Eur. J. Med. Chem. 2011, 46, 765-772.

21. Musa, M.A.; Badisa, V.L.; Latinwo, L.M.; Cooperwood, J.; Sinclari, A.; Abdullah, A. Cytotoxic activity of new acetoxycoummarin derivatives in cancer cell lines. Anticancer Res. 2011, 31, 2017-2022.

22. Bronikowska, J.; Szliszka, E.; Jaworska, D.; Czuba, Z.P.; Krol, W. The Coumarin Psoralidin Enhances Anticancer Effect of Tumor Necrosis Factor-Related Apoptosis-Inducing Ligand (TRAIL). Molecules 2012, 17, 6449-6464. 
23. Roma, G.; di Braccio, M.; Grossi, G.; Piras, D.; Leoncini, G.; Bruzzese, D.; Signorello, M.G.; Fossa, P.; Mosti, L. Synthesis and in vitro antiplatelet activity of new 4-(1-piperazinyl)coumarin derivatives. Human platelet phosphodiesterase 3 inhibitory properties of the two most effective compounds described and molecular modeling study on their interactions with phosphodiesterase 3A catalytic site. J. Med. Chem. 2007, 12, 2886-2895.

24. Dekić, B.R.; Radulović, N.S.; Dekić, V.S.; Vukićević, R.D.; Palić, R.M. Synthesis and antimicrobial activity of new 4-heteroarylamino coumarin derivatives containing nitrogen and sulfur as heteroatoms. Molecules 2010, 15, 2246-2256.

25. Chimenti, F.; Bizzarri, B.; Bolasco, A.; Secci, D.; Chimenti, P.; Granese, A.; Carradori, S.; Rivanera, D.; Zicari, A.; Scaltrito, M.M.; et al. Synthesis, selective anti-Helicobacter pylori activity, and cytotoxicity of novel $\mathrm{N}$-substituted-2-oxo-2H-1-benzopyran-3-carboxamides. Bioorg. Med. Chem. Lett. 2010, 20, 4922-4926.

26. Kulkarni, A.; Patil, S.A.; Badami, P.S. Synthesis, characterization, DNA cleavage and in vitro antimicrobial studies of $\mathrm{La}(\mathrm{III}), \mathrm{Th}(\mathrm{IV})$ and $\mathrm{VO}(\mathrm{IV})$ complexes with Schiff bases of coumarin derivatives. Eur. J. Med. Chem. 2009, 44, 2904-2912.

27. Zavrsnik, D.; Muratovic, S.; Spirtovic, S.; Softic, D.; Medic-Saric, M. The synthesis and antimicrobial activity of some 4-hydroxycoumarin derivatives. Bosn. J. Basic Med. Sci. 2008, 8, 277-281.

28. Siddiqui, Z.N.; Musthafa, T.N.M.; Ahmad, A.; Khan, A.U. Synthesis of 4-hydroxycoumarin heteroarylhybrids as potential antimicrobial agents. Arch. Pharm. (Weinheim) 2011, 344, 394-401.

29. Basanagouda, M.; Shivashankar, K.; Kulkarni, M.V.; Rasal, V.P.; Patel, H.; Mutha, S.S.; Mohite, A.A. Synthesis and antimicrobial studies on novel sulfonamides containing 4-azidomethyl coumarin. Eur. J. Med. Chem. 2010, 45, 1151-1157.

30. Rehman, S.U.; Chohan, Z.H.; Glunaz, F.; Supuran, C.T. In-vitro antibacterial, antifungal and cytotoxic activities of some coumarins and their metal complexes. J. Enzyme Inhib. Med. Chem. 2005, 20, 333-340.

31. Guo, Q.; Liu, M.L.; Feng, L.S.; Lv, K.; Guan, Y.; Guo, H.Y.; Xiao, C.L. Synthesis and in vitro antimycobacterial activity of fluoroquinolone derivatives containing a coumarin moiety. Arch. Pharm. (Weinheim) 2011, 344, 802-809.

32. Chiang, C.C.; Cheng, M.J.; Peng, C.F.; Huang, H.Y.; Chen, I.S. A novel dimeric coumarin analog and antimycobacterial constituents from Fatoua pilosa. Chem. Biodivers. 2010, 7, 1728-1736.

33. Upadhyay, K.; Bavishi, A.; Thakrar, S.; Radadiya, A.; Vala, H.; Parekh, S.; Bhavsar, D.; Savant, M.; Parmar, M.; Adlakha, P.; et al. Synthesis and biological evaluation of 4-styrylcoumarin derivatives as inhibitors of TNF- $\alpha$ and IL-6 with anti-tubercular activity. Bioorg. Med. Chem. Lett. 2011, 21, 2547-2549.

34. Kampranis, S.C.; Gormley, N.A.; Tranter, R.; Orphanides, G.; Maxwell, A. Probing of Coumarins and Cyclothialidines to DNA Gyrase. Biochemistry 1999, 38, 1967-1976.

35. Wang, H.X.; Ng, T.B. Examination of lectins, polysaccharopeptide, polysaccharide, alkaloid, coumarin and trypsin inhibitors for inhibitory activity against human immunodeficiency virus reverse transcriptase and glycohydrolases. Planta Med. 2001, 67, 669-672.

36. Maoa, P.C.; Mouscadet, J.F.; Leh, H.; Auclair, C.; Hsu, L.Y. Chemical modification of coumarin dimmer and HIV-1 integrase inhibitory activity. Chem. Pharm. Bull. 2002, 50, 1634-1637. 
37. Le, B.G.; Radanyi, C.; Peyrat, J.F.; Brion, J.D.; Alami, M.; Marsaud, V.; Stella, B.; Renoir, J.M. New novobiocin analogues as antiproliferative agents in breast cancer cells and potential inhibitors of heat shock protein90. J. Med. Chem. 2007, 50, 6189-6200.

38. Lin, L.H.; Lee, L.W.; Sheu, S.Y.; Lin, P.Y. Study on the stevioside analogues of steviolbioside, steviol, and isosteviol 19-alkyl amide dimers: synthesis and cytotoxic and antibacterial activity. Chem. Pharm. Bull. 2004, 52, 1117-1122.

Sample Availability: Samples of the compounds 14-21 are available from the authors.

(C) 2012 by the authors; licensee MDPI, Basel, Switzerland. This article is an open access article distributed under the terms and conditions of the Creative Commons Attribution license (http://creativecommons.org/licenses/by/3.0/). 